\title{
Paramagnetic species in catalysis research: a unified approach towards (the role of EPR in) heterogeneous, homogeneous and enzyme catalysis
}

\author{
Maruan Bracci, ${ }^{a}$ Paolo Cleto Bruzzese, ${ }^{b}$ Antonino Famulari, ${ }^{a}$ \\ David Fioco, ${ }^{c}$ Andrea Guidetti, ${ }^{\boldsymbol{d}}$ Yu-Kai Liao, ${ }^{\boldsymbol{e}}$ \\ Leonora Podvorica, ${ }^{e}$ Seyedeh Fardokht Rezayi, ${ }^{c}$ Ilenia Serra, ${ }^{d}$ \\ Kavipriya Thangavel ${ }^{b}$ and Damien M. Murphy*c \\ DOI: 10.1039/9781839162534-00001
}

\begin{abstract}
Paramagnetic (open-shell) systems, including transition metal ions, radical intermediates and defect centres, are often involved in catalytic transformations. Despite the prevalence of such species in catalysis, there are relatively few studies devoted to their characterisation, compared to their diamagnetic counterparts. Electron Paramagnetic Resonance (EPR) is an ideal technique perfectly suited to characterise such reaction centres, providing valuable insights into the molecular and supramolecular structure, the electronic structure, the dynamics and even the concentration of the paramagnetic systems under investigation. Furthermore, as EPR is such a versatile technique, samples can be measured as liquids, solids (frozen solutions and powders) and single crystals, making it ideal for studies in heterogeneous, homogeneous and enzyme catalysis. Coupled with the higher resolving power of the pulsed, higher frequency and hyperfine techniques, unsurpassed detail on the structure of these catalytic centres can be obtained. In this Chapter, we provide an overview to demonstrate how advanced EPR methods can be successfully exploited in the study of open-shell paramagnetic reaction centres in heterogeneous, homogeneous and enzymatic catalysts, including heme-based enzymes for use in biocatalysts, polymerisation based catalysts, supported microporous heterogeneous catalytic centres to homogeneous metal complexes for small molecule actions.
\end{abstract}

\section{Introduction}

Within the chemical sciences, catalysis remains a vitally important field of research. Indeed, continued developments in new or improved catalysts is essential to meet the future challenges in delivering the raw materials or products underpinning fuels, water and the environment, healthcare, energy, food, and resources sustainability. In all cases, catalysts will be necessary since they offer an extremely energy efficient means of providing these valuable chemicals. Despite their phenomenal success, further enhancements and improvements in their efficiency requires a greater understanding of how they operate, and more

\footnotetext{
${ }^{a}$ Department of Condensed Matter Physics, Faculty of Sciences, University of Zaragoza, Calle Pedro Cerbuna 12, 50009, Zaragoza, Spain

${ }^{\boldsymbol{b}}$ Felix Bloch Institute for Solid State Physics, Universität Leipzig, Linnéstr. 5, 04103 Leipzig, Germany

${ }^{c}$ School of Chemistry, Main Building, Cardiff University, Cardiff CF10 3AT, UK.

E-mail: MurphyDM@cardiff.ac.uk

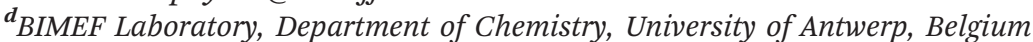

${ }^{e}$ Department of Chemistry, University of Turin, Via Giuria 9, 10125-Torino, Italy
} 
specifically on the mechanistic pathways responsible for converting reactants into products. This inevitability requires the application of advanced techniques that can probe the catalytic reaction, ideally with spatial or temporal resolution, under reaction conditions. However, another equally insightful direction for understanding reaction profiles, is to detect, characterize and monitor the various reaction intermediates involved in the step-wise catalytic cycle.

Indeed, chemical reactions are ultimately controlled by two fundamental parameters, namely energy (including free and activation energy) and angular momentum (involving the spin) of the reactants and products. As a consequence of this, reactivity patterns often depend critically on the presence of paramagnetic (open-shell) intermediates. Elucidating the role and influence of such open-shell intermediates in any catalytic cycle is presently one of the most challenging endeavours in this field of research, both from an experimental and theoretical perspective. The rewards for undertaking such research endeavours are considerable if the many successful (but also generally expensive and toxic) noble metal based catalysts can be replaced by (generally cheap and non-toxic) earth abundant metals.

Certainly, in the case where paramagnetic centres are involved, Electron Paramagnetic Resonance (EPR), and the associated advanced range of pulsed, hyperfine or high frequency techniques, are without doubt essential for investigating and fully interrogating the paramagnetic component of the reaction system. Nevertheless, the technique is still largely underexploited in the field of catalysis research, since it often requires highly specialised equipment and expertise to collect and interpret the data. In this Chapter, we will therefore illustrate the outstanding success of EPR to uncover new chemical secrets in the field of catalysis, by focusing more broadly on homogeneous, heterogeneous and enzymatic based catalysts. Within this broad domain of catalysis research, we will cite specific examples ranging from heme-based enzymes for use in biocatalysts, to homogeneous and supported polymerisation systems (including Ziegler-Natta, Philips and oligomerisation based catalysts), to microporous heterogeneous systems (such as zeolites and metal organic frameworks) to homogeneous complexes active in small molecule actions (such as homogeneous catalytic centres, systems for catalytic alcohol oxidation to $\mathrm{C}-\mathrm{C}$ cross coupling). Despite the varying nature of the catalytic active site in all these systems, the analytical approach offered by EPR to interrogate the active species, remains unifying, simple and similar; in all cases, we seek to probe the nature of the local paramagnetic system and it's longer range interactions with the surrounding nuclei through the spin Hamiltonian and where possible compare this to computational data. Through this approach, detailed insights into the mechanism and active intermediates involved in the reaction cycle can be examined with unsurpassed detail.

\section{Heme enzymes as biocatalysts}

In recent times, the increasing demand for a reduction in the environmental impact of industrial processes has resulted in the search for 
greener alternative processes. The field of biocatalysis has attracted increasing popularity, particularly with the advent of modern biotechnology. The term biocatalysis refers to the use of enzymes, or entire microorganisms, to perform industrially relevant chemical transformations, an activity whose origins dates back to the beginning of the 20th century. Biocatalysis is generally considered as sustainable process because of their many distinctive characteristics, including non-toxicity, mild reaction conditions, compatibility with aqueous solvents, and ability to generate pure products due to their high (enantio-) selectivity. However, some challenges remain with respect to the widespread utilisation of these biocatalysts, including their stability and reusability, the costs associated with downstream processing, and the time-to-market pressure which often favours more consolidated methods. ${ }^{1,2}$

Within this field, a well-known and diverse group of biocatalysts is based on the heme enzymes. They belong to the larger class of heme proteins, which are widespread biomolecules in nature, holding a diverse range of functionalities. For example, the versatility of the heme group is often exploited in activities such as oxygen storage and transport, electron transfer, signal transduction and catalysis. ${ }^{3}$ For the purpose of this section, the following discussion will focus on the latter aspects of their function. In the IUPAC Compendium of Chemical Terminology, "heme" is defined as a macrocyclic system containing an iron centre coordinated to a porphyrin ring which acts as a tetradentate ligand, and to one or two additional axial ligands. ${ }^{4}$ The reactivity of heme enzymes is governed both by the chemistry at the heme iron centre, and the interaction of the prosthetic group with the protein moiety. Biological redox reactions involve electron transfer processes, for which efficiency is optimised when the free energy driving force $(\Delta G)$ is maximised and the reorganisation energy $(\lambda)$ is minimised, in accordance with Marcus's theory. ${ }^{5}$ In heme systems, the electron delocalisation over the porphyrin ring reduces the need for re-ordering in the local structure. As a result, the thermodynamics is defined by the redox potential of the couple donor-acceptor, which in the case of heme enzymes, is regulated by the protein matrix. ${ }^{6}$

Among the representative heme-types found in biology (labelled $a, b, c$, $d_{1}$ ), the best studied is probably the heme $b$ (iron protoporphyrin IX), common to the oxygenase and peroxidase families (Fig. 1). These two broad classes of heme enzymes, which oxidise substrates utilising dioxygen and hydrogen peroxide respectively, ${ }^{7}$ will be discussed later.

The iron centre in heme systems can be found in various oxidation states, the most common of which are $\mathrm{Fe}^{2+}, \mathrm{Fe}^{3+}$ and $\mathrm{Fe}^{4+}$. The first two states are commonly found in two different spin configurations, either high-spin or low-spin, depending on the distribution of electrons in the d-orbitals, whose degeneracy is removed by the ligand field splitting. The $\mathrm{Fe}^{4+}$ oxidation state is of notable importance for the catalytic mechanism of many heme enzymes, existing in transient states, which are formed during the turnover cycle upon binding of the activator substrate. Indeed, the key intermediates in the reaction cycle are often described as $\mathrm{Fe}^{4+}$-oxo species, known as Compound I and Compound II. The former stores two oxidising equivalents, one on the iron, and one in the form of a free radical. 


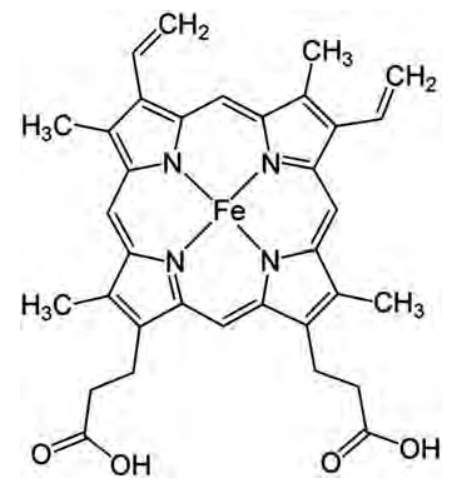

Fig. 1 Schematic structure of heme $b$.

Table 1 Electronic configurations of iron in heme systems.

\begin{tabular}{llll}
\hline & $\mathrm{Fe}^{2+}$ & $\mathrm{Fe}^{3+}$ & $\mathrm{Fe}^{4+}$ \\
\hline High spin & $S=2$ & $S=5 / 2$ & - \\
Low spin & $S=0$ & $S=1 / 2$ & $S=1$ \\
\hline
\end{tabular}

After one-electron reduction, the free radical is lost, resulting in the formation of Compound II. ${ }^{8}$ A summary of the variable oxidation and spin states occurring in heme system are listed in Table 1.

In heme proteins, the metal centre commonly adopts an pseudo octahedral coordination mode, with four equatorial nitrogen atoms from the porphyrin ring and a protein residue as proximal axial ligand in the fifth position, typically a histidine, cysteine or tyrosine. The sixth axial position can either be occupied by another endogenous ligand, an external molecule (such as water), or even left free (uncoordinated) to promote substrate binding. Coordination by the porphyrin ring places the iron d-orbitals in an intermediate ligand field, close in energy to the 'low-spin to high-spin' transition, so that the spin state is sensitive to the nature of these axial ligands. A "strong" ligand will cause a splitting of the $e_{g}$ and $t_{2 g}$ orbitals, larger than the pairing energy that is necessary to keep two electrons in the same orbital. Only the lower energy $t_{2 g}$ orbitals will be occupied, leading to a low-spin configuration. Alternatively, a "weak" ligand will have an orbital energy separation small enough to prefer the occupancy of the $e_{g}$ orbitals, thus contributing to a high-spin configuration. ${ }^{9}$

Since almost all of these iron states are paramagnetic, EPR spectroscopy is one of the most suitable techniques for the investigation of heme-based systems. Moreover, even if proteins are large, complex molecules, the EPR characterisation method is still reliable as it focuses specifically on the paramagnetic active site, where the unpaired electrons reside. In metalloproteins possessing iron centres with multiple unpaired electrons $(S>1 / 2)$, the zero-field splitting (ZFS) term can be much larger than the X-band microwave quantum. In the case of high spin $\mathrm{Fe}^{3+}$, the observed EPR spectrum is derived exclusively from transitions within the Kramers doublets, and it can be treated as an effective $S=1 / 2$ system $^{10}$ (Fig. 2). However, for a more accurate description of the 

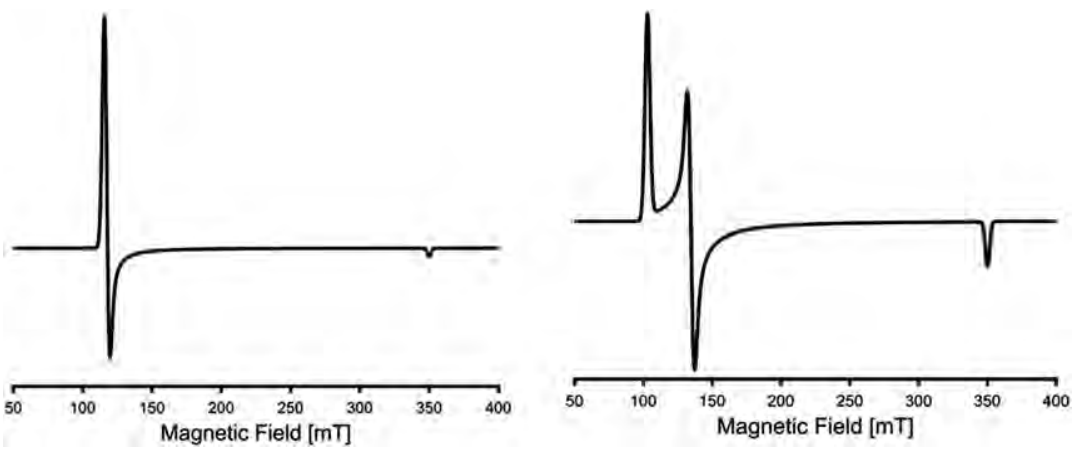

Fig. 2 Illustrative continuous wave (CW) EPR spectra of high-spin $\mathrm{Fe}^{3+}(S=5 / 2)$ heme based centres simulated using the Easyspin ${ }^{\mathbb{R}}$ package, with $g_{\perp}$ eff $\approx 6, g_{\|}{ }^{\text {eff }} \approx 2$ for the axial case (left); $g_{x}{ }^{\text {fff }} \approx 6.4, g_{y}{ }^{\text {eff }} \approx 5.2, g_{z}{ }^{\text {eff }} \approx 2$ for the rhombic case (right).

spin system, two independent parameters denoted as the tetragonal zerofield splitting $(D)$ and rhombic zero-field splitting $(E)$ terms, can be derived from the principal values of the $\boldsymbol{D}$ tensor, which describe the zero-field splitting interactions in the spin Hamiltonian. The defined ratio $\eta=E / D$ (with $0<\eta<1 / 3$ ) is called the rhombicity term, and is commonly used in the simulations of X-band CW EPR spectra of heme proteins with high spin multiplicity since they depend, to a good approximation, on this single parameter. ${ }^{11}$

Another example of high-spin iron is $\mathrm{Fe}^{2+}$ with $S=2$, characterised by four unpaired electrons. Despite being an EPR-active species in principle, very few examples of high spin ferrous heme have been reported in literature. ${ }^{12,13}$ The detection of this non Kramer ion is impeded by the large ZFS which removes the $\Delta m_{\mathrm{s}}= \pm 1$ levels above the accessible microwave energy i.e. the allowed transition. At X-band, only at very low applied magnetic fields can a broad structureless feature be detected. For these reasons it is generally assumed that the high-spin ferrous complexes are EPR silent at X-band. ${ }^{12}$

Low-spin $\mathrm{Fe}^{3+}(S=1 / 2)$ is commonly found in heme structures possessing strong axial ligands. In contrast to the high-spin states, this spin state can be represented by a simpler spin Hamiltonian, in which the zero-field splitting terms are absent, and thus a more readily interpreted EPR spectrum (Fig. 3).

The $g$-values for low-spin ferric heme proteins are very often interpreted with a crystal field model that correlates them to the relative energy splitting of the iron $t_{2 g}$ orbitals, ${ }^{14,15}$ and therefore the corresponding spin distribution. How, and to what extent the electron system is affected by the axial substituents, can be related to the nature of the axial ligands and the active-site geometry. ${ }^{16-18}$ A different case of low-spin iron occurs in its reduced state $\left(\mathrm{Fe}^{2+}, S=0\right)$, although this species is not paramagnetic, having six paired electrons in the outer valence shell which fully occupy the $t_{2 g}$ orbitals due to the large separation from the ligand field. It is clear that whilst iron heme proteins possess diverse and variable electron configurations that may be challenging to study, they nevertheless offer highly desirable application in modern catalysis. In the following sections, more 

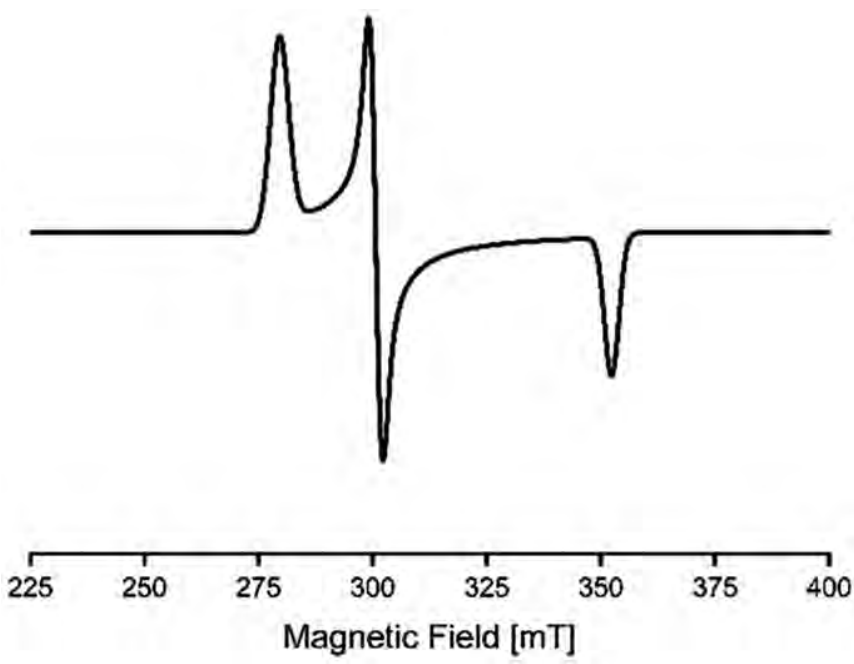

Fig. 3 Illustrative CW EPR spectrum of a low-spin $\mathrm{Fe}^{3+}(S=1 / 2)$ heme based centre simulated using the Easyspin ${ }^{\mathbb{R}}$ package with $g_{z}=2.42, g_{y}=2.25, g_{x}=1.92$.

specific examples will be presented to demonstrate their applicability and reaction versatility as aerobic oxidation catalysts, and importantly how EPR can be exploited to understand their reaction cycles.

\subsection{Compound I in heme systems}

Although a great deal of uncertainty exists around the first reactive intermediate in heme-based systems, most of the literature reports concur that the catalytic activity starts with the species commonly (but

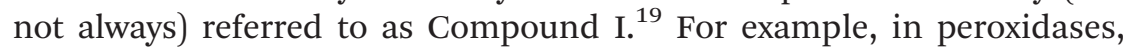
Compound I is responsible for a diverse assortment of industrially relevant reactions including enantioselective epoxidation of olefins, oxidation of amines, alcohols and sulphides, as well as peroxidase-catalysed polymerisation of aromatic molecules. For this reason, peroxidases have historically received greater attention for their potential application in the field of biocatalysis. ${ }^{20}$ In P450s for example, vide infra, it performs oxygenation reactions, whilst in catalases, it facilitates peroxide disproportionation. This serves to defend aerobic organisms by breaking down toxic hydrogen peroxide into water and molecular oxygen. ${ }^{21}$

During the catalytic cycle, all these enzymes oxidise the iron above the ferric Fe(III) resting state to form Compound I, a high-valent iron(Iv)-oxo intermediate $^{8}$ (see Scheme 1 below). The formation of this intermediate occurs following the heterolytic cleavage of the substrate $\mathrm{O}-\mathrm{O}$ bond, which leads to the storage of two oxidising equivalents, one that resides in iron(Iv), and another one somewhere in the protein. Several

$$
\begin{gathered}
-\mathrm{Fe}^{3+}-+\mathrm{ROOH} \rightarrow-\left(\mathrm{Fe}^{4+}=\mathrm{O}\right)-\cdot+\mathrm{ROH} \\
-\mathrm{Fe}^{3+}-+\mathrm{O}_{2}+2 \mathrm{H}^{+}+\mathrm{e} \rightarrow-\left(\mathrm{Fe}^{4+}=0\right)-\cdot+\mathrm{H}_{2} \mathrm{O}
\end{gathered}
$$

Scheme 1 
observations indicate that it could reside on the porphyrin ring, or in a tryptophan (Trp), tyrosine (Tyr) or cysteine (Cys) residue of the protein, more commonly in the form of a cationic free radical. ${ }^{7}$

In Scheme 1, $\mathrm{R}$ can be a hydrogen or an organic group, whereas the labels - - represent the porphyrin ring and proximal ligand (His, Tyr or Cys), with oxygen representing the sixth ligand.

Numerous techniques have been used to unravel the complexities surrounding the characterisation of Compound I, but it remains a challenging task in part due to the transient nature of this intermediate and its correspondingly high reactivity. EPR plays a crucial role in characterising such intermediates, largely because both oxidising equivalents of Compound I form paramagnetic states readily detected by the technique. To date, several CW EPR spectra of Compound I with distinct features have been reported in the literature for different systems. They are usually described by a model consisting of two interacting spin systems, one from the heme iron $(S=1)$ and one from a free radical $(S=1 / 2)$. The spin distribution on the oxo-ferryl moiety is generally modelled by taking into account an almost purely axial zero field splitting, which is sensitive to the ligand environment. The main interaction between the iron and the free radical, is the so-called exchange interaction, a weak spin-spin interaction that is caused by the partial overlap of the wave functions of the two paramagnetic centres. This interaction varies in strength and sign, which is highly dependent on the electron distribution of both species. This ultimately determines the net spin state of Compound I. $^{19,22-25}$

It should also be noted that, although the ZFS is very sensitive to the molecular structure, the magnitudes reported for $\mathrm{Fe}(\mathrm{Iv})=\mathrm{O}$ in heme enzymes are usually much larger than the energy of the MW quantum (especially at X-band), thereby shifting the transitions outside the accessible magnetic field range. ${ }^{26}$ Whilst the oxo-ferryl moiety is EPR silent, the electronic levels of $\mathrm{Fe}(\mathrm{Iv})$ affect the relaxation properties of the interacting radical species. CW EPR relaxation studies have therefore been used to obtain the ZFS parameters of $\mathrm{Fe}(\mathrm{IV})=0$ in some enzymes. ${ }^{22,27}$

When the radical resides on the porphyrin ring, or on a residue close enough to the iron centre, then the EPR spectrum of Compound I appears broad and can be interpreted by considering the exchange interaction..$^{28,29}$ On the other hand, if the radical resides on an amino acid (this intermediate is variously referred to as Compound ES, Compound $\mathrm{I}^{*}$ or Compound $-\mathrm{I}_{\mathrm{B}}{ }^{30-33}$ ), and is sufficiently remote from the iron centre, then no orbital overlap occurs. As a consequence, the exchange interaction is negligible and the shape of the EPR spectrum is dominated by the non-coupled organic radical contribution. ${ }^{30}$ Interestingly, the nature of the amino acid in which the radical is stored can be determined from the CW EPR spectrum assuming some of the characteristic hyperfine interactions can be resolved by suitable techniques.

In most reported cases, the small hyperfine interactions between the electron spin and magnetic nuclei in Compound I, are completely unresolved in the CW EPR spectra. In these cases, more advanced hyperfine spectroscopies are required to resolve these small interactions. For example, CW and pulsed Electron Nuclear DOuble Resonance 
(ENDOR) spectroscopies have been used to fully characterize the location of the free radical and spin distribution on the active site in heme enzymes. $^{34-36}$ The ENDOR technique, combined with isotopic substitutions of Compound I in Horseradish Peroxidase, has provided detailed insights into hyperfine couplings between the free radical and ${ }^{1} \mathrm{H},{ }^{14} \mathrm{~N}$ nuclei which originate from the porphyrin ring, indicating that the ferryl moiety is not protonated. Using ${ }^{17} \mathrm{O}$ labelling, it was found that the oxygen from the peroxide is transferred to the iron(Iv)-oxo species where one of the oxidizing equivalent is stored. ${ }^{37,38}$ In addition to this information on spin-distribution, complimentary information on local structural aspects, can also be derived from the resolved hyperfine data. For example, using multi-frequency EPR and ENDOR, the ${ }^{1} \mathrm{H}$ hyperfine coupling observed in a Trp radical-type Compound I of peroxidase, was used to calculate the dihedral angles of the aromatic radical and thus, with the aid of crystallographic structures, DFT and site directed mutagenesis, identify the exact position of the radical in the protein. ${ }^{39,40}$

It is known that a multitude of factors can tune the reactivity of Compound I. Such factors can include the nature and distance of the iron proximal ligand to the metal centre, which can be a histidine (as in peroxidases), a cysteine (as in P450s) or a tyrosine (as in catalase). Another important factor is the polarity of the protein cavity, to which the oxygen of Compound I is exposed, and where the reaction with the substrates can occur. This was determined by several amino acid residues, which were more or less conserved among the different proteins. The reactivity can also be influenced by the propionate groups of the heme, which are used to anchor this prosthetic group to the protein moiety. These are expected to destabilise the cationic radical hosted in the porphyrin if they are not involved in polar bonds. Finally, the network of hydrogen bonds that involves the entire active site, and its geometry, is also known to play a fundamental role that affects the reactivity. ${ }^{41-43}$ These factors appear to depend on where the radical is located, which is crucial for the reaction mechanism involving the intermediate.

The power of EPR to characterise these heme-based systems is certainly enhanced by complementary QM/MM calculations. The ab initio calculation of the electronic density, confined to the active site, enables one to compute magnetic-resonance parameters including the $\boldsymbol{g}$ tensor, and $\boldsymbol{A}$ tensors for remote surrounding nuclei. Usually, several models are required to fully describe the spin system, taking into account different regions of the proteins, spin distributions, hydrogen bonds, etc. However, only by comparison with experimental data, such as EPR, is it possible to validate and determine the accuracy of the computed model. One of the standard outputs of the calculations are the hyperfine constants that can be directly compared with the experimental parameters obtained by advanced hyperfine techniques. ${ }^{44,45}$

It is clear that to understand the mechanism of these heme-based catalysts, it is fundamentally important to determine the electronic distribution, and the nature of the reactive intermediates. In the future, further studies involving hyperfine spectroscopies will be required to better understand the role of these paramagnetic spin states in the reactivity of 
compound I. The experimental results, coupled with theoretical calculations, will serve to clarify the nature of these intermediates. This endeavour remains challenging however, owing to the difficulties of isolating and stabilising Compound I on such short timescales. In these cases, a rapid freeze-quench approach is required. The purity of the enzyme is also sometimes overlooked as an important parameter, crucial to aid in the characterisation of such proteins. A good example, which has puzzled the scientific world for decades, is the isolation of compound I from P450. This was achieved by focusing on an extremely high purification of the enzyme which crucially influences the stability of the intermediate. ${ }^{46}$

In summary, EPR can certainly provide a highly informative insight into the electronic structure of the heme-based systems. In most cases, valuable information can be obtained by straightforward CW EPR measurements at X-band $(9.5 \mathrm{GHz})$ microwave frequencies, whilst the most fruitful array of information can only be revealed using the more advanced pulsed EPR techniques, including high-field EPR, ENDOR, ESEEM and HYSCORE capabilities.

\subsection{Chlorite dismutases}

Heme peroxidases are oxidoreductases which feature a heme prosthetic group in their active site. According to a recent phylogenetic classification, ${ }^{47}$ within the peroxidase-chlorite dismutase superfamily is the heme $b$ containing enzyme chlorite dismutase (Cld), which catalyses the decomposition of chlorite $\left(\mathrm{ClO}_{2}{ }^{-}\right)$into chloride $\left(\mathrm{Cl}^{-}\right)$and molecular oxygen $\left(\mathrm{O}_{2}\right)$. First described in 1996 by Van Ginkel and co-workers, ${ }^{48}$ chlorite dismutases were initially found in perchlorate-reducing bacteria (PCRB), which are facultative anaerobes utilising perchlorate $\left(\mathrm{ClO}_{4}{ }^{-}\right)$and chlorate $\left(\mathrm{ClO}_{3}{ }^{-}\right)$as the final electron acceptors in the absence of oxygen. Considerable interest remains in the chlorite dismutases because of their unique ability to catalyse the formation of an oxygen-oxygen bond, and their biotechnological potential in the field of bioremediation, particularly in relation to the rising levels of chlorite concentrations in drinking water and soil. ${ }^{49}$

Chlorite dismutases are currently classified into two lineages, namely Clade I containing homohexa- and pentameric-enzymes, and Clade II comprising the less well characterised dimeric representatives. Notwithstanding the overall structural differences between these two Clades, the active-site architecture and the crucial amino acids can be essentially superimposed. A fully conserved histidine acts as fifth proximal ligand for the ferric heme iron, whilst at the distal site a conserved flexible arginine is also the only charged residue in a completely hydrophobic pocket. ${ }^{50}$ Crystal structures of chlorite dismutases demonstrated that this residue can adopt two different conformations, denoted as "in" when pointing towards the iron or "out" when pointing away from the heme. It has been suggested that the arginine could either be involved in substrate recognition, or in preventing the transiently formed intermediates to escape from the active-site, ${ }^{51}$ but its role needs to be further elucidated.

In the resting state of chlorite dismutases, a water molecule generally acts as a weak distal ligand for the heme iron. This is supported by UV-visible 
spectroscopy, which shows that at neutral $\mathrm{pH}$, chlorite dismutases possess the typical spectral features of a penta-coordinated high-spin iron centre. ${ }^{50}$ Due to the paramagnetic nature of $\mathrm{Fe}^{3+}$, more detailed insights into the active site configuration can be obtained by means of EPR spectroscopy, which has been extensively applied in numerous studies on chlorite dismutases. In particular, CW X-band EPR spectroscopy in frozen solution revealed that chlorite dismutases from Clade I typically exhibit rhombically distorted high-spin spectra at neutral $\mathrm{pH}^{.}{ }^{52-55}$ In contrast, the few representatives from Clade II investigated so far, are characterised by purely axial high-spin signals. ${ }^{55-57}$ Minor contributions from low-spin components were also detected by EPR at $\mathrm{pH}=7$. In some cases, the low-spin signals observed at neutral $\mathrm{pH}$ were assigned to an imidazole adduct (strong ligand), derived from protein purification procedures involving a His-tag affinity step. ${ }^{58}$ However, this could be ruled out for recombinant chlorite dismutases, which were purified without the use of imidazole; in these systems low-spin components of uncertain origin are often observed. ${ }^{55,59}$

Chlorite dismutase activity has been shown to be critically influenced by $\mathrm{pH}$, having an optimum activity between $5.0-5.5$, and a significant decrease in the reaction rate at higher $\mathrm{pH}$ values. ${ }^{51,56}$ EPR spectroscopy was also exploited in $\mathrm{pH}$-dependence studies, revealing the formation of hydroxide-ligated heme iron at alkaline $\mathrm{pH},{ }^{53,57,59}$ which could contribute to slowing of the turnover rate. The reason for this dramatic change upon $\mathrm{pH}$ variation, is only one of many unresolved questions involved in the catalytic cycle of chlorite dismutases. An in-depth analysis of the numerous proposed pathways cannot be adequately treated in this Chapter, although a general description will be presented here to highlight how EPR spectroscopy can provide unique mechanistic insights into how these enzymes operate.

A commonly accepted reaction mechanism is presented in Fig. 4. In this mechanism, the anionic substrate initially binds to the ferric resting state of the enzyme (labelled step 1), forming an $\mathrm{Fe}^{3+}-\mathrm{ClO}_{2}{ }^{-}$complex (step 2). During this step, the flexible arginine is believed to move from

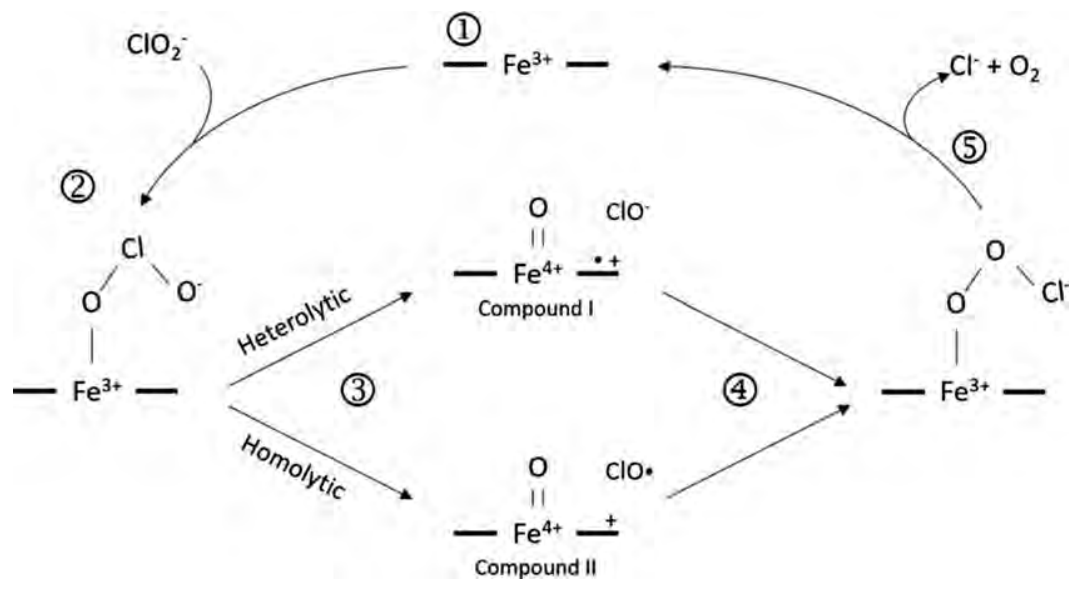

Fig. 4 Schematic illustration of the proposed catalytic cycle for chlorite dismutases. 
the "out" to the "in" conformation. Then, the cleavage of the chlorite molecule occurs (step 3), with a subsequent rebinding step (step 4), before the products are released (step 5). ${ }^{50}$ The main uncertainty concerning this reaction is whether chlorite is cleaved via a heterolytic or homolytic mechanism, resulting in oxidation of the heme iron to a Compound I or Compound II species respectively; with subsequent formation of either hypochlorite $\left(\mathrm{ClO}^{-}\right)$as intermediate in the first case, or chlorine monoxide $(\mathrm{ClO} \bullet)$ in the second case. So far, homolytic cleavage has been supported by computational studies, ${ }^{60,61}$ whilst biochemical evidences have favoured the heterolytic pathway. ${ }^{51,62}$ Nevertheless, recent investigations on a dimeric Clade II chlorite dismutase, ${ }^{32}$ showed the apparent direct transition from the resting state, to a Compound II species in the range of $\mathrm{pH} 5-9$, while the formation of a Compound I species was postulated as a side reaction at acidic $\mathrm{pH}$.

As expected from this mechanism, a transient radical is formed either on the porphyrin $\pi$-cation, or on the substrate intermediate. In addition, the decay of the porphyryl radical to a protein-based radical (Compound I*), due to internal electron transfer to a nearby amino acid, has also been proposed for a pentameric Cld. ${ }^{54}$ The identification and exact nature of the transient radical is not trivial to characterise, and for this reason EPR spectroscopy has played a pivotal role is these studies, since radicals of different origin exhibit distinct spectral features in frozen solution. The major hindrance to studies of these reaction intermediates is the time-scale limitation. Stopped-flow UV-vis spectroscopy showed that the dominant transient species is formed within a few milliseconds from the addition of chlorite, and that it persists as long as chlorite is available, which is on the order of a few seconds using the experimental conditions applied until now. ${ }^{32,51}$ Due to technical aspects associated with sample preparation times for EPR analysis, little data is available on the reaction of chlorite dismutases with their substrate. In fact, only two examples of EPR analysis on the turnover of these enzymes have been reported to date. In the work of Lee et al., ${ }^{54}$ on chlorite dismutase from Dechloromonas aromatica, the protein sample containing chlorite was flash-frozen in liquid nitrogen within one second. The authors observed the complete loss of spectral features associated with the ferric enzyme, and the concomitant appearance of a broad and a sharp signal. These were assigned to an $S=3 / 2$ porphyrin $\pi$-cation radical (Compound I), and a tryptophanyl radical, respectively. In a more recent study by Hofbauer and co-workers, ${ }^{51}$ the pentameric enzyme from Candidatus nitrospira defluvii was mixed with different amounts of chlorite, but in this case the reaction was allowed to go to completion before the sample was analysed using EPR. With increasing concentrations of chlorite, the high-spin signal of the resting state progressively disappeared, with no concomitant formation of low-spin species. At very high excess of chlorite ( $>2500$-fold), a protein radical was observed. These results were consistent with the hypothesis of an irreversible enzyme inactivation mechanism, also supported by UV-visible spectroscopy.

It is clear that EPR spectroscopy remains invaluable in studies of chlorite dismutases. Using less active variants, which can be obtained with relative ease by site-directed mutagenesis, working under different 
$\mathrm{pH}$ conditions and sample preparations using a freeze-quench apparatus, some of the existing technical limitations encountered in this field can be overcome, revealing new insights and discoveries into this fascinating series of enzymes.

\subsection{Cytochromes P450}

Another exceedingly important member of the heme superfamily ${ }^{63}$ of enzymes is CYP450. ${ }^{64}$ The name for these enzymes is derived from the spectral properties of the cytochrome (CY) and heme-pigment (P) which displays a shift of the typical Soret optical absorption band maximum to $450 \mathrm{~nm}$ in the $\mathrm{Fe}^{2+}-\mathrm{CO}$ bound state. ${ }^{65}$

From a functional viewpoint, CYP450s are versatile and ubiquitous monooxygenases which principally catalyse hydroxylation of nonactivated hydrocarbons. ${ }^{66}$ This elementary reaction delivers different results, such that some organisms use it as a way to degrade and digest carbon, ${ }^{67}$ whilst others (such as mammals) use it to metabolize endogenous chemicals, and purify the organism from xenobiotics like drugs and medicines. ${ }^{68}$ The remarkable functional diversity also extends to biosynthesis of steroids and epoxidation of olefins. ${ }^{69,70}$ By exploiting a concerted electron and proton transfer mechanism, operating at the active site of the protein, an oxygen atom from dioxygen can be attached with high specificity to a very wide range of substrates, as represented by the reaction:

$$
\mathrm{R}-\mathrm{H}+\mathrm{O}_{2}+2 \mathrm{e}^{-}+2 \mathrm{H}^{+} \rightarrow \mathrm{R}-\mathrm{OH}+\mathrm{H}_{2} \mathrm{O}
$$

An electron flow is established from an electron donor, normally $\mathrm{NAD}(\mathrm{P}) \mathrm{H}$, and directed through other cofactors, located in the physiological partners or other domains of the protein, to the heme containing P450 domain.

From a structural viewpoint, the iron atom located at the centre of the heme is the main protagonist of the active site. It can coordinate six ligands in an octahedral environment. The metal binds to four nitrogen atoms from the pyrroles of the porphyrin ring, and invariably a cysteine, through a thiolate coordination bond connected to the protein. The sixth axial position is open to the substrate pocket where the reaction takes place, and the occupancy of this site changes sequentially throughout the catalytic cycle, from a water molecule in the resting state, to an empty vacancy when the substrate binds to an oxygen molecule in the catalytic cycle.

The general catalytic cycle of P450 enzymes is illustrated in Fig. 5. Crucially, several different paramagnetic intermediates are generated throughout the cycle. EPR spectroscopy has therefore become an essential technique for interrogating the catalytic cycle. The primary states, and their associated paramagnetic species, include:

The resting state (1). The ferric iron is a $d^{5}$ paramagnetic ion, and $\mathrm{CW}$ EPR can thus provide detailed information on the electronic configuration and orbital geometry, including the obvious confirmation of the low spin $(S=1 / 2)$ configuration. CW ENDOR and Pulse EPR experiments have revealed numerous weak hyperfine interactions of the ferric heme centre, mainly nitrogen and hydrogen nuclei from the porphyrin and 


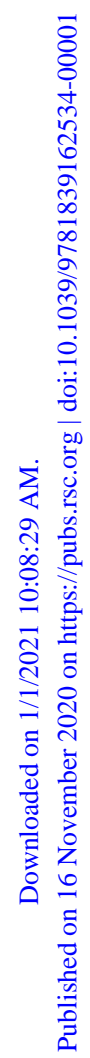

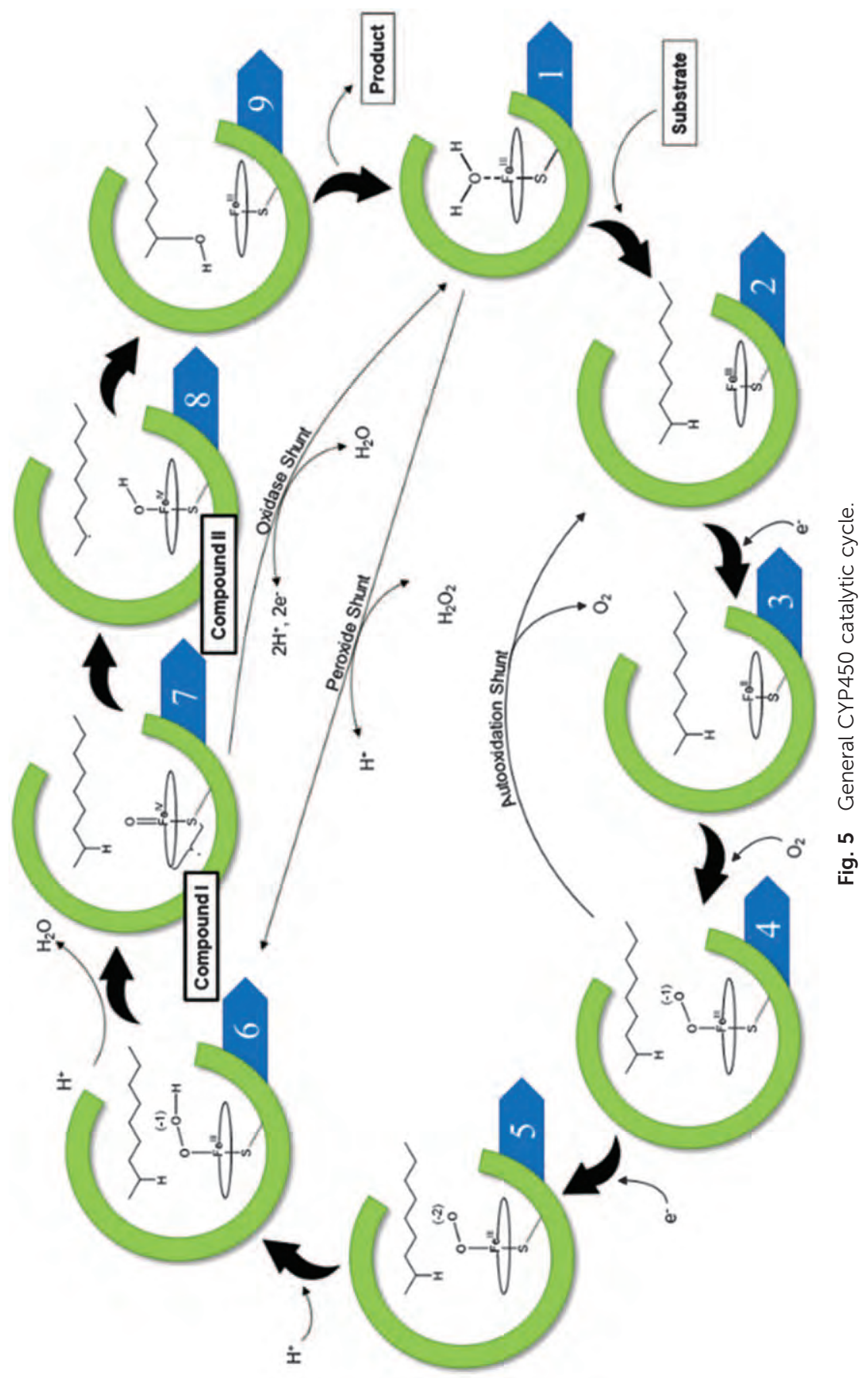


axial substituents. In fact, evidence of iron-water binding in the resting state was provided by ENDOR and four-pulse ESEEM techniques, that gave a direct measure of the anisotropic hyperfine interaction for the water protons. ${ }^{71,72}$ The study of these hyperfine interactions also revealed the orientation of the orbital geometry in in the resting state of P450s.

The substrate-bound ferric state (2). When the enzyme binds the substrate close to the distal site, the water molecule is subsequently displaced, and the five-coordinated iron changes electron configuration to high-spin (HS) or to a mixture of HS and LS states. ${ }^{17}$ The EPR spectrum is very sensitive to changes in the coordination number or geometry of the iron, and therefore the technique has been used to detect changes in the heme pocket by substrate binding: ${ }^{73}$ Also, the decrease in linewidth of the ferric iron EPR signals in the bound-state, can be interpreted as a structural stabilisation brought about by substrate binding. Conformational enzyme changes of P450cam was detected using DEER experiments by exploiting the distance distributions between two spin labels, attached at the surface of the enzyme, on opposite sides of the substrate access channel. ${ }^{74}$

Ferrous dioxygen and Ferric superoxide states (3)/(4). When the first electron is transferred to the $\mathrm{Fe}^{\mathrm{III}}$ centre, it causes reduction to $\mathrm{Fe}^{\mathrm{II}}$ which was discovered to be the rate determining step of the cycle. ${ }^{75}$ Although the iron in this state could be paramagnetic, only a few studies have been performed to date in such systems, owing to technical challenges (discusssed vide infra). This species has been observed and characterised using X-ray spectroscopy. ${ }^{76}$

Peroxo-Ferric and Hydroperoxo intermediates (5)/(6). Following the addition of a second electron to the centre, a peroxo-ferric species is formed. The transfer of a proton to the dioxygen moiety then produces a hydroperoxo intermediate. Detailed and numerous EPR studies on these intermediates have shed light on their characteristic electron configuration, and chemical nature. These intermediates are very hard to accumulate in the natural cycle, and therefore various research groups have exploited techniques including cryoreduction and annealing, in order to monitor changes to the iron system and ligand binding. ${ }^{35}$

Compound $I$ (7). After a second proton transfer, a water molecule is subsequently released from the active site leaving an $\mathrm{Fe}^{\mathrm{IV}}=\mathrm{O}$ intermediate, which is referred to as Compound I and represents the true catalytic species of the whole cycle. This intermediate has been observed recently, by CW EPR and other techniques, in several members of the family using the peroxide shunt, which reacts with the resting state with peroxides/peracids. ${ }^{78}$ The electronic characteristics of this species have been described vide infra in section 2.1.

Rebound mechanism and product (8)/(9). Once Compound I has formed, it catalyses the hydroxylation reaction through a mechanism that is still poorly understood and widely debated, even if many scientist agree on a rebound-type mechanism. In this iron state, a hydrogen atom is removed from a certain position on the substrate, and bound to oxygen followed by the formation of an hydroxyl group, which rebinds rapidly to the radical substrate forming the product. ${ }^{79}$ 
In all stages of the catalytic cycle, EPR has undoubtedly played an essential role in deciphering the nature of the chemical intermediates, and the catalysis occurring in these proteins. However, many unanswered questions remain. In recent years, there is emerging evidence and interest focusing on the use of CYP450 enzymes not just as monooxygenase, but as peroxygenases by using the peroxide shunt. ${ }^{80}$ Indeed, as it can be seen in Fig. 5, the catalytic cycle of CYP450 can be productive using hydrogen peroxide. Through this path, Compound I can be obtained directly from the resting state of the protein. The advantage of this reaction is that catalysis is performed without using expensive electron donors, such as $\mathrm{NAD}(\mathrm{P}) \mathrm{H}$ and without involvement of other protein partners and oxygen, but simply using hydrogen peroxide or peracids as their substitutes. Unfortunately, despite their great potential, these substrates are strong oxidants. Following a number of catalytic cycles, irreversible damage occurs to the cytochromes, which in turn greatly reduces their activity. Recently, several CYP450s were discovered that can undertake the catalysis using $\mathrm{H}_{2} \mathrm{O}_{2}$ without damage, namely a CYP450 enzyme called CYP116B5. ${ }^{81}$ This cytochrome shows remarkable stability in the presence of peroxide, and a peroxygenase-like reactivity. This behaviour is quite peculiar. For instance, in CYPBM $3,{ }^{82}$ a cytochrome with which it shares almost the same electron transfer topology, showed the classic CYP450 behaviour of undergoing damage from interaction with peroxides. Reaction assays, where the interaction between $\mathrm{H}_{2} \mathrm{O}_{2}$ and these two comparative proteins was studied, revealed that as the concentration of $\mathrm{H}_{2} \mathrm{O}_{2}$ increased from $0 \mathrm{mM}$ to $5 \mathrm{mM}$, the activity of CYPBM3 decreased by $80 \%$, whilst that of CYP116B5 only decreased by $10 \% .{ }^{83}$ All this ensures that CYP116B5 may find interesting potential use in biocatalysis as a highly performing, reliable, cheap and eco-friendly catalyst.

For all these reasons, a better understanding of the behaviour and reactivity of CYP450 enzymes is crucial to underpin future developments in catalysis. A considerable amount of research has already been undertaken on these systems, whilst new emerging discoveries on species such as CYP116B5, demonstrate the wealth and potential yet to be uncovered in this important class of enzymes. EPR spectroscopy will thus continue to play a pivotal role in studying these underpinning paramagnetic mechanisms.

\section{Catalysts for polymerisation}

The exceedingly successful catalytic activities and functions, delivered by enzymes, are of course well known. Indeed, the success and specificity achieved by enzymes is unparalleled and unmatched by any synthetic catalysts. However, one area of synthetic catalysis where yields and turnovers are quite remarkable, is in the field of polymerisation. This is best exemplified from the widespread successful use of Ziegler-Natta and Phillips based catalysts for olefin polymerisation, and also more recently for $\mathrm{Cr}$ based catalysts used in oligomerisation. In these catalysts, paramagnetic intermediates or oxidation states are frequently involved and central to the catalytic cycle. As a result, EPR once again has become an 
indispensable tool for the characterisation, and thus improvement of these catalytic reactions.

In general, polymerisation and oligomerisation catalysts behave in very different ways, but ultimately they do share a few common traits. An ethylene molecule, or another olefin (such as propylene), will usually coordinate to the metal centre using the electron density of the double bond (this 2 electron, 3 centre bond has a hapticity number of $\eta^{2}$ ). In this position, the molecule has a greater chance to interact with another olefin. The ability of the metal centre to thereby switch between oxidation states, crucially enables the coordinated reagents to undertake insertion reactions, such as oxidative coupling. Each insertion step extends the growing chain by one unit. Ziegler Natta catalysts for ethylene or propylene polymerization can grow linear chains of thousands of carbon atoms, while in the case of the chromium catalysts for ethylene oligomerization the chain growth occurs through the formation of a metallacycle. Ring geometry restrictions typically limit the maximum length to 2, 3 or 4 monomers.

Analogous to the role played by EPR in the characterisation of enzymes, local information of the paramagnetic metal sites in the polymerisation and oligomerisation reaction centres can be revealed with exquisite detail. One of the most relevant paramagnetic metal ions in olefin polymerization is $\mathrm{Ti}^{3+}$, whereas paramagnetic $\mathrm{Cr}^{1+/ 3+}$ states are crucially important in oligomerisation processes. The distortion of the local geometry of paramagnetic metal centres in the activated, and reactive catalysts, is manifested through the spin Hamiltonian parameters, including the $g$ tensors for $\mathrm{Ti}^{3+}$ and low spin $\mathrm{Cr}^{1+}$, and the additional ZFS terms for the $\mathrm{Cr}^{3+}$ centres. For systems with half-integer spin (Kramers species), the experiment can be readily performed at conventional microwave frequency $(9.5 / 34 \mathrm{GHz}$ for $\mathrm{X}$-/Q-band), whereas the "EPRsilent" integer spin systems (non-Kramer species) require high-field/ high-frequency EPR (HFEPR) measurements to fully interpret the paramagnetic state. Other advanced EPR techniques, including ENDOR, ELDOR detected NMR, ESEEM, and HYSCORE, have been successfully used to probe the other nuclei in the coordination sphere. The results combined from these techniques can provide an unrivalled view of the structures and chemical bonds between metal sites and ligands, which will be illustrated in the following sections.

\subsection{Ziegler-Natta catalysts}

Ziegler - Natta catalysts (ZNC) represent one of the most important discoveries within the polymerisation industry. Their discovery by Karl Ziegler in 1954 lead to a breakthrough in the synthesis of ethylene at room temperature, and enabled Giulio Natta to polymerise propylene into crystalline polypropylene for the first time in 1954. ZNC can be based on homogeneous (including Ti, Zr and Hf complexes) and heterogeneous (including Ti complexes) catalysts. The characterisation of the heterogeneous $\mathrm{ZNC}$ is exceedingly challenging, compared to their homogeneous counterparts bearing a single active site ${ }^{84,85}$ in part owing to the presence of multiple active sites. The distribution and heterogeneity of the active sites, can then be discriminated using EPR, since as stated 
above, the spin Hamiltonian parameters are sensitive to changes in the local coordination environment around the metal centre.

In heterogeneous $\mathrm{ZNC}$ the reactions occur at specific active sites formed by $\mathrm{TiCl}_{4}$ located on the surface of a highly active $\mathrm{MgCl}_{2}$ support $\left(\mathrm{SiO}_{2}, \mathrm{TiO}_{2}, \mathrm{MgO}\right.$, and $\mathrm{Al}_{2} \mathrm{O}_{3}$ supports have also been reported $\left.{ }^{86}\right)$, and activated using a suitable co-catalyst consisting of a main group metal alkyl (generally an aluminum alkyl). The active sites are presumed to be paramagnetic $\mathrm{Ti}^{3+}$ species featuring a metal-carbon bond, generated by the reduction of the supported $\mathrm{Ti}^{4+}$ centre by the co-catalyst. ${ }^{85}$ The over-reduction of $\mathrm{Ti}^{4+}$ to $\mathrm{Ti}^{2+}$ and $\mathrm{Ti}^{+}$has also been reported. ${ }^{87}$ Lewis bases are added to the system as additional components, not only to improve the activity of the catalyst, but also to enhance and control the stereoregularity that primarily affects the crystallinity of the polymer. ${ }^{88,89}$ The presence of a large number of potentially active components in the catalyst, complicates the detailed microscopic understanding of the inner working mechanism of these heterogeneous ZNCs. The activity, selectivity and specificity of the catalyst's active site are determined from each of the individual components, and even subtle changes in the coordination sphere of the active sites can lead to substantial changes in the catalytic performance. A thorough characterisation of these catalysts at the molecular level, in terms of electronic, chemical, and structural properties is required, although complicated by the heterogeneity of the support, the low concentration of the active sites, and the ease of contamination. Nevertheless, EPR and the advanced hyperfine techniques can provide the desired information, particularly when complimented using suitable computational work. ${ }^{90}$

The paramagnetic $\mathrm{Ti}^{3+}$ center, bearing a simple $d^{1}$ electron configuration $(S=1 / 2)$, is most readily characterised by EPR spectroscopy. ${ }^{90}$ $\mathrm{CW}$ and Pulse EPR techniques then provide a unique insight into the geometric, electronic structure, and the surrounding environment of the paramagnetic $\mathrm{Ti}^{3+}$ active sites. Such information is extracted through the electron Zeeman interaction (characterized by the $g$ matrix) and the hyperfine interactions of the unpaired electron with local spin active nuclei ${ }^{47} \mathrm{Ti}$ and ${ }^{49} \mathrm{Ti}$, and more remote surrounding nuclei in the first and even second coordination spheres, including ${ }^{1} \mathrm{H},{ }^{17} \mathrm{O},{ }^{27} \mathrm{Al}$ and ${ }^{35,37} \mathrm{Cl}$ nuclei. ${ }^{90-92}$ Representative examples that illustrate how the coordination environment of $\mathrm{Ti}^{3+}$, with ethylene association in model systems can be investigated by EPR, have been reported recently. ${ }^{92-94}$ Most of the published EPR spectra include overlapped signals arising from different $\mathrm{Ti}^{3+}$ species with either axial $\left(g_{\perp}>g_{\|}\right.$and $\left.g_{\perp}<g_{\|}\right)$or rhombic $\left(g_{x} \neq g_{y} \neq g_{z}\right) g$ values ranging from 1.89 to 1.99 . The deviations in the $g$ values may be attributed to a different genesis, all of which are related to the influence of the chemical environment on the paramagnetic species. Some of the most common reasons, for the slight deviation of the $g$ values in the ZNC, include the localisation of $\mathrm{Ti}^{3+}$ species at different surface terminations of $\mathrm{MgCl}_{2}$ support (lateral cut 110 and 104), the nature of Lewis bases and even the nature of the co-catalyst used in the activation process. ${ }^{92,95,96}$

Brant et al., ${ }^{96}$ described an EPR investigation on a model ZNC prepared by the deposition of alkylmagnesium butoxide (AMB) and titanium 
tetrachloride onto a silica support. Their work did not provide much insight regarding the structures of the active sites themselves, responsible for the reported $g$ values $(g=1.99,1.957,1.951)$, except for a signal at $g=1.895$, but they provide an important correlation between Ti spin concentrations and different $\mathrm{Ti} / \mathrm{Mg}$ ratios. Increasing the $\mathrm{Ti}-\mathrm{Mg}$ ratio was found to lead to higher signal intensities for the lower $g$ values and higher activity of the catalyst in ethylene polymerization, while decreasing $\mathrm{Ti}-\mathrm{Mg}$ ratio lead to higher signal intensity for higher $g$-values. Using a wet chemical route, they demonstrated that the amount of $\mathrm{Ti}^{3+}$ and $\mathrm{Ti}^{2+}$ formed after the reduction of $\mathrm{Ti}^{4+}$ was $95 \%$ and $0.8 \%$ respectively. However, the total amount of EPR active $\mathrm{Ti}^{3+}$ detected only represented $10-20 \%$ of all the titanium, suggesting the presence of considerable quantities of EPR silent $\mathrm{Ti}^{3+}$ centres. ${ }^{95}$ The exact identity of these EPR silent $\mathrm{Ti}^{3+}$ species remains unclear, but it is likely attributed to clustered organisations of titanium active sites, which results in antiferromagnetically - EPR silent-coupled states. ${ }^{97}$

In a series of papers, Koshevoy and co-workers ${ }^{99-101}$ detailed an EPR investigation of super-active supported titanium-magnesium catalysts, with a low titanium content $(\leq 0.1 \mathrm{wt} . \%)$, which was activated with aluminum trialkyls of different composition. The formation of isolated $\mathrm{Ti}^{3+}$ species, with slightly different $g$ values, was reported which corresponded to commonly reported $g$ values for ZNC. The EPR active $\mathrm{Ti}^{3+}$ species in these systems represented $40-70 \%$ of the total titanium content, higher than for conventional catalysts. The content of EPR active $\mathrm{Ti}^{3+}$ species was found to rely on the composition of the co-catalyst, and was correlated to the activity of the catalyst in ethylene polymerization and ethylene copolymerization with $\alpha$-olefins.

Morra et al., ${ }^{93}$ investigated an industrial catalyst consisting of $\mathrm{TiCl}_{4} /$ $\mathrm{MgCl}_{2} /$ dibutylphthalate, activated by triethylaluminum (TEA). The presence of three distinct EPR-active $\mathrm{Ti}^{3+}$ species was reported, two of them being more dominant than the third. The measurements were performed using a combination of multi-frequency ( $\mathrm{X}, \mathrm{Q}$, and $\mathrm{W}$ band) $\mathrm{CW}$ and pulse EPR techniques (including HYSCORE and ELDOR-detected NMR). The $g$ values extracted from the X- and W-band spectra were reported as $g_{1}=1.93, g_{2}=1.88$ and $g_{3}=1.89$ for the first species 1 (with $76 \%$ abundance), $g_{1}=1.96, g_{2}=1.94$ and $g_{3}=1.89$ for the second species 2 (with $23 \%$ abundance) and finally $g_{1}=1.97, g_{2}=1.96$ and $g_{3}=1.96$ (with only $1 \%$ abundance) for the third species 3. From the Q-band HYSCORE spectra, a hyperfine coupling between $\mathrm{Ti}^{3+}$ and ${ }^{35,37} \mathrm{Cl}$ was observed, suggesting a direct coordination of $\mathrm{Cl}$ nuclei to the two more abundant $\mathrm{Ti}^{3+}$ species. The catalyst was subsequently exposed to molecular oxygen, to demonstrate the reactivity and the accessibility of the EPR active sites. A decrease of the $\mathrm{Ti}^{3+}$ signal intensity was observed immediately, due to oxidation to the EPR silent $\mathrm{Ti}^{4+}$ centre along with the concomitant appearance of surface superoxide $\left(\mathrm{O}_{2}{ }^{-}\right)$signal. The latter superoxide signal was used as a spin probe to reveal the presence of Al nuclei, originating from the co-catalyst, in close proximity to the $\mathrm{Ti}^{3+}$ species. Moreover, a hyperfine interaction with ${ }^{1} \mathrm{H}$ nuclei was resolved in X-band HYSCORE measurements, translating into an $\mathrm{O}_{2}^{-} \ldots \mathrm{H}$ distance of 
$0.33 \mathrm{~nm}$. Finally, analysis of the Q-band HYSCORE revealed that the large isotropic (Fermi contact) hyperfine interaction with ${ }^{27} \mathrm{Al}$, indicated that the $\mathrm{O}_{2}{ }^{-}$radical is stabilized on the $\mathrm{Ti}^{4+}$ centre and experiences a direct interaction with the ${ }^{27} \mathrm{Al}$ nucleus of the co-catalyst. ${ }^{92}$

Advanced EPR studies were also used to provide meaningful information on the nature of paramagnetic metal-olefin complexes. These experiments, performed on ZNCs, revealed important information on the $\pi$-coordination mode of the olefins at the paramagnetic center, and thus in turn informed on how the stereoselectivity of the catalyst is directed. In particular, standard HYSCORE and SMART-HYSCORE experiments (the latter providing higher sensitivity and an absence of any blind spots), in combination with DFT calculations, were performed by Morra et al. ${ }^{95}$ The study was performed on mono-ethylene complexes with trivalent titanium centres, produced by adsorption of $\mathrm{C}_{2} \mathrm{H}_{4}$ and ${ }^{13} \mathrm{C}$-enriched $\mathrm{C}_{2} \mathrm{H}_{4}$ on reduced TiAlPO- 5 zeotype materials. This study provided experimental proof for the $\pi$-coordination of ethylene to the paramagnetic $\mathrm{Ti}^{3+}$ centre, in addition to the electronic and geometric structure of the ethylene- $\mathrm{Ti}^{3+}$ intermediate complex. The HYSCORE spectrum revealed the presence of two distinct ${ }^{13} \mathrm{C}$ couplings, confirming that the two carbon nuclei of ethylene are inequivalent, with $\mathrm{C}_{2}$ displaying a larger coupling to the Ti compared to $\mathrm{C}_{1}$. This affirmed an asymmetry in the spin density delocalisation between the two carbons of ethylene. From this study, it was shown that the reactivity of the ethylene molecule and the stereoselectivity of the catalyst are as a consequence of the electronic effects. ${ }^{94}$

Another study was performed by Allouche et al. ${ }^{94}$ using HYSCORE in combination with X-ray crystallography and DFT calculations, to investigate two model systems of low coordinated bis(alkoxide) $\mathrm{Ti}^{3+}$ alkyl complexes formed upon ethylene polymerisation. In this study, they provided structural assignment for $\left(\equiv \mathrm{Si}_{2} \mathrm{O}\right)(\equiv \mathrm{SiO})_{2} \mathrm{Ti}^{3+}-\mathrm{R}$ surface species as key intermediates in the ethylene polymerisation activity of the silicasupported titanium hydrides. From the CW EPR spectra, they observed rhombic $\boldsymbol{g}$ tensors for both complexes, bearing different degrees of $g$-anisotropy. After the reaction of the complexes with ${ }^{13} \mathrm{C}$-labelled ethylene, weak ${ }^{1} \mathrm{H}$ couplings were observed in the HYSCORE spectra to the first coordination sphere of $\mathrm{Ti}^{3+}$, and the closest proton to the $\mathrm{Ti}^{3+}$ centre was found to be from the $\mathrm{C}_{\alpha}$ carbon of the alkyl ligand. The HYSCORE spectra also showed the characteristic ${ }^{13} \mathrm{C}$ hyperfine coupling. ${ }^{93}$

Whilst most of the reported systems to date are based on the paramagnetic $3 d^{1} \mathrm{Ti}^{3+}$ oxidation state, the $3 d^{2}$ configuration of $\mathrm{Ti}^{2+}$ can also be paramagnetic, when present as a high spin triplet state $(S=1)$; however very few EPR studies of $\mathrm{Ti}^{2+}$ are reported. ${ }^{96}$ Nevertheless, some studies have employed an indirect route to study $\mathrm{Ti}^{2+}$ with EPR, using selective oxidising reactions of $\mathrm{Ti}^{2+}$ to $\mathrm{Ti}^{3+}$, using water or pentafluorochlorobenzene:

$$
\begin{gathered}
2 \mathrm{Ti}^{2+}+2 \mathrm{H}_{2} \mathrm{O} \rightarrow 2 \mathrm{Ti}^{3+}+2 \mathrm{OH}^{-}+\mathrm{H}_{2} \\
\mathrm{TiCl}_{2}+\mathrm{C}_{6} \mathrm{~F}_{5} \mathrm{Cl} \rightarrow \mathrm{TiCl}_{3}+\mathrm{C}_{6} \mathrm{~F}_{5}
\end{gathered}
$$

In other studies, EPR has also been used to identify and study the organic radicals formed after activation of the pre-catalyst with the 
co-catalyst. The origin of the organic radicals is generally found to be due to the presence of internal and external electron donors. ${ }^{101}$

Clearly, as described above, EPR offers a powerful means to characterise the active sites on ZNC and their surrounding environment. Whilst most of these studies have utilized the more readily available CW EPR method, the advantages offered from pulsed EPR techniques offers a far greater step forward in terms of the information that can be extracted from the unresolved hyperfine interactions on the structure of the active sites.

\subsection{Phillips based systems}

The Phillips catalyst was discovered by J. P. Hogan and R. L. Banks at Phillips Petroleum in the 1950s. ${ }^{102}$ It is a Cr-based catalyst used for ethylene polymerisation and its use is so widespread that it accounts for over $40 \%$ of the high-density polyethylene (HDPE) commercially available. Despite being successfully utilised in large scale industrial operations for the past 60 years, it may be rather surprising to learn that there are still many unanswered questions concerning the mode of operation of the catalysts. ${ }^{103-105}$ In particular, the oxidation state and geometry of the active site is still poorly understood, whilst some of the fundamental steps involved in the polymerisation mechanism remain elusive.

These questions remain unresolved for several reasons. First, only a small fraction of the Cr-sites are actually active, such that many studies have actually reported upon indirect Cr-species. Second, the Phillips catalyst itself represents a rather complex arrangement of chemical entities, which are sensitive to the experimental conditions. As a result, experiments conducted in different research laboratories may have employed slightly different conditions, giving rise to slightly different distribution of centres within the catalyst. Third, most laboratory studies were conducted on high vacuum lines which often do not reproduce the experimental conditions employed in industrial applications, and therefore the observer is actually reporting on different states of the catalyst. In general terms, the Phillips catalysts are prepared by dispersing hexavalent chromium ions onto the surface of porous inorganic materials. ${ }^{105}$ The catalyst is then activated by calcination in an oxidising atmosphere at temperature above $600{ }^{\circ} \mathrm{C}$. After the activation step, $\mathrm{Cr}^{6+}$ will be the dominating $\mathrm{Cr}$ species, with a minor proportion of $\mathrm{Cr}^{5+}$ species. ${ }^{106}$

There are two common forms of the Phillips catalyst, namely the oxidised form and the reduced form. The oxidised form is based on the aforementioned $\mathrm{Cr}^{6+}$ precatalyst. It can react with ethylene at $\mathrm{T}>100{ }^{\circ} \mathrm{C}$, and initiate polymerisation after the induction time. During the induction period, the chromium is reduced to lower oxidation state, predominantly $\mathrm{Cr}^{2+}$, before forming the Cr-R active sites (for which the oxidation state is uncertain). The small amount of $\mathrm{Cr}^{5+}$ centres (with $S=1 / 2$ ), can be investigated by X-/Q-band EPR, and these usually reveal an axial set of $g$ values when grafted on alumina support. On the other hand, two $\mathrm{Cr}^{5+}$ centres with axial and rhombic $g$ values were reported for the silica grafted material. ${ }^{107,108}$ Upon ethylene polymerisation, high spin Cr species, characterized by signals with $g_{\text {eff }} \sim 4.3$, can also be detected. 
These were attributed to $\mathrm{Cr}^{3+}$ species $(S=3 / 2)$ with large ZFS parameters, ${ }^{108}$ and illustrate the complexity of speciation in these catalysts.

By comparison, the reduced form of the Phillips catalyst can be obtained by further reducing the oxidised form with CO. At $350{ }^{\circ} \mathrm{C}$, the $\mathrm{Cr}^{6+}$ sites can be quantitatively converted to $\mathrm{Cr}^{2+}$. After this reduction, the catalyst is active for polymerisation with ethylene at room temperature, without an induction time. EPR investigations of these catalysts showed that only a small amount of $\mathrm{Cr}^{5+}$ remained as an impurity after the reduction. ${ }^{108-110}$ The non-Kramers $\mathrm{Cr}^{2+}$ species $(S=2)$ was investigated using high field EPR at 106/212/317 GHz, and was reported to have a very small rhombicity for the ZFS tensor. ${ }^{109}$ Upon ethylene polymerisation, two research groups reported different observations, albeit under slightly different conditions. In one case, the X-/Q-band spectrum was reported to be unaltered following ethylene exposure at room temperature, ${ }^{108}$ and assumed that no Kramers species was involve in the polymerisation. However, in another study the polymerisation reaction was performed at $T=80{ }^{\circ} \mathrm{C}$ and the authors reported the appearance of $\mathrm{Cr}^{3+}$ signals, characterised by the broad linewidth, centred at $g \sim 1.98$ with axial symmetry, together with the loss from $\mathrm{Cr}^{2+}$ signals. ${ }^{109,110}$ Therefore, it was concluded that the $\mathrm{Cr}^{2+}$ sites were oxidised to organo- $\mathrm{Cr}^{3+}$ species by ethylene, which initiated the polymerisation.

As described above, both forms of the Phillips catalysts require a reduction step forming the $\mathrm{Cr}^{2+}$ centres. The polymerisation mechanism is then proposed to operate via a two electron redox process involving $\mathrm{Cr}^{2+}$ and $\mathrm{Cr}^{4+}$, or a one electron redox process involving $\mathrm{Cr}^{2+}$ and $\mathrm{Cr}^{3+}$. To delineate which mechanism is operative, considerable efforts in surface organometallic chemistry (SOMC) and supported homogeneous catalysis (SHC) have created systems bearing surface chromium sites with welldefined oxidation state and nuclearity on a silica-/alumina surface. ${ }^{111}$ This is exemplified by the research from Copéret and colleagues. ${ }^{112,113}$ In their studies, $\mathrm{Cr}^{3+}$-siloxide and $\mathrm{Cr}^{3+}$-amide were grafted onto the silica surface. In the case of the $\mathrm{Cr}^{3+}$-siloxide, two high spin $\mathrm{Cr}^{3+}$ species with $g_{\text {eff }} \sim 4.9$ were detected in the X-band EPR spectrum, together with hyperfine couplings to ${ }^{29} \mathrm{Si}$ at $2.99 \mathrm{MHz}$ identified in the HYSCORE experiment. On the other hand, the grafted $\mathrm{Cr}^{3+}$-amide produced an EPR signal with with $g_{\text {eff }} \sim 2$, attributed to low spin $\mathrm{Cr}^{3+}(S=1 / 2)$ whilst the HYSCORE spectrum revealed a hyperfine coupling to ${ }^{14} \mathrm{~N}$ at $1.05 \mathrm{MHz}$.

Bearing in mind the limitations stated earlier, it is crucial to investigate the complex Phillips catalyst with a plethora of analytical and spectroscopic techniques, if the mechanism is to be truly understood. As shown above, EPR is one such spectroscopic technique that can provide detailed information on the local geometry of the $\mathrm{Cr}$ species and even the surrounding environment using advanced technique such as HYSCORE. Kramers species including $\mathrm{Cr}^{3+}$ and $\mathrm{Cr}^{5+}$ can be investigated at conventional microwave frequencies employed in EPR (i.e., X-/Q-band), whilst higher microwave frequencies are needed to investigate the non-Kramers species like $\mathrm{Cr}^{2+}$ and $\mathrm{Cr}^{4+}$. The potential opportunities afforded by pulsed EPR are undoubtedly yet to be explored, but owing to the complex speciation and distribution of spin active centres in these catalysts, it will always 
remain challenging to fully characterise the paramagnetic centres in these catalysts. Nevertheless, EPR will remain a vitally important tool in the arsenal of techniques used to study the Philips Catalysts.

\subsection{Oligomerisation based systems}

Oligomerisation is a similar process to polymerisation, but aimed at assembling shorter molecular chains and preferably with a well defined chain length. One of the commonly employed processes is the oligomerisation of ethylene, as it is the simplest of all building blocks (monomers) available. The products of ethylene oligomerisation are called linear $\alpha$-olefins (LAO), which can be as short as 1-butene, but do not have a specific maximum chain length limit. 1-hexene and 1-octene are the most desirable product chain lengths for this type of reaction. Chromium-based catalysts, in conjunction with aluminium co-catalysts, have proven to be highly effective for this reaction, and the Phillips trimerisation system (not to be confused with the above Philips polymerisation catalyst) is currently used to produce large quantities of 1-hexene. ${ }^{114}$

More recently, ${ }^{115}$ it was discovered that the chromium based organometallic complexes, based around the general structure $\left[\mathrm{Cr}(\mathrm{CO})_{4}\left(\mathrm{Ph}_{2} \mathrm{PN}-\right.\right.$ $\left.\left.(\mathrm{i}-\mathrm{Pr}) \mathrm{PPh}_{2}\right)\right]^{+}$have excellent oligomerisation activity and, like the previous catalysts already employed in industry, is activated using a large excess of a co-catalyst, such as triethylaluminium (TEA) or methylaluminoxane (MAO). The co-catalyst is used to remove the carbonyl ligands in the complex. However, a wide variety of species are formed during this activation step and indeed the catalytically active species remain uncertain, whilst the full scope of the secondary reactions induced by these agents remains uncertain. Following the activation of the catalyst, two ethylene molecules bind to the Cr metal centre. At first the substrate is thought to bind through the double bond, whilst in the second stage, two ethylene molecules undergo oxidative coupling, which alters the oxidation state of the chromium centre by +2 . Chain growth occurs in consecutive insertion stages after the formation of the first 5-membered ring. As additional ethylene molecules are inserted, larger 7- and 9- membered rings are formed, with the metal centre acting as one of the vertices. The specific metal complex used, including the choice of phosphine ligands and the reaction conditions, can all be tuned to selectively produce 1-butene, 1-hexene or 1-octene.

Similar to the case described vide infra for the Phillips based catalyst, the redox states of chromium that are operative in the catalytic cycle for the oligomerisation systems are also unknown. A two electron redox couple is believed to occur in the chromium oligomerisation catalyst, involving either $\mathrm{Cr}^{1+}$ and $\mathrm{Cr}^{3+}$ (both paramagnetic) or involving $\mathrm{Cr}^{2+}$ and $\mathrm{Cr}^{4+} \cdot{ }^{114}$ Indeed chromium possess several accessible oxidation states, ranging from 0 to VI, and many of these are paramagnetic. The low spin states involving $\mathrm{Cr}^{1+}, \mathrm{Cr}^{3+}$ or $\mathrm{Cr}^{5+}$, are not affected by ZFS, and are therefore relatively easy to study at conventional microwave frequencies used in EPR. As stated earlier, the high spin states can be more problematic to characterise, unless the user has access to high field EPR measurements. 
Nevertheless, the sheer abundance of potential paramagnetic centres involved in the oligomerisation catalysts has meant that EPR has played a crucial role in the characterisation of such systems, especially when used in conjunction with other techniques and computational chemistry. ${ }^{114}$

As previously explained, large quantities of aluminium based cocatalysts are required to activate the chromium pre-catalyst. There are numerous reasons why this abundance of co-catalyst is far from ideal. First, from a pure atom economy perspective, it makes the reaction less efficient by adding to the reagents whilst also requiring later separation from the clean product. Second, there are many by-products which are not believed to be catalytically active. And finally, the exhausted salts are an environmental hazard which cannot easily be disposed of nor recycled. ${ }^{115}$

To date, a number of EPR studies have been conducted using X-band CW techniques ${ }^{116,117}$ to determine the oxidation states and structure of the $\mathrm{Cr}^{3+}$ based catalyst $\left[\mathrm{Cr}(\mathrm{acac})_{3}\left(\mathrm{Ph}_{2} \mathrm{PN}(\mathrm{i}-\mathrm{Pr}) \mathrm{PPh}_{2}\right)\right]_{3}$, both during the activation step with $\mathrm{Al}$ agents, and during the actual oligomerisation. By comparison, other groups have studied the $\mathrm{Cr}^{1+}$ based catalyst, $\left[\mathrm{Cr}(\mathrm{CO})_{4}\left(\mathrm{Ph}_{2} \mathrm{P}\left(\mathrm{CH}_{2}\right)_{3} \mathrm{PPh}_{2}\right)\right]^{+}$and $\left[\mathrm{Cr}(\mathrm{CO})_{4}\left(\mathrm{Ph}_{2} \mathrm{PN}(\mathrm{i}-\mathrm{Pr}) \mathrm{PPh}_{2}\right)\right]^{+}$, following activation with TEA. ${ }^{117}$ When low levels of TEA are used a $\operatorname{Cr}(\mathrm{I})$ bis-arene complex, $\left[\mathrm{Cr}\left(\mathrm{Ph}_{2} \mathrm{P}\left(\mathrm{CH}_{2}\right)_{3} \mathrm{PPh}_{2} \text {-bis- } \eta^{6} \text {-arene }\right)\right]^{+}$was formed, as revealed by EPR and DFT. This bis-arene complex was proposed to form via intramolecular rearrangement and co-ordination of $\mathrm{Cr}^{1+}$ to the phenyl groups of the phosphine ligand in aliphatic solvents, following loss of CO. It was thought that this prevents release of $\mathrm{Cr}^{1+}$ ions into solution. On the contrary, when aromatic solvents were employed such as toluene, a bis-tolyl complex was preferentially formed. The same group also studied the activation when higher levels of TEA were employed. ${ }^{118}$ It was clear that the TEA was responsible for the complete removal of all CO groups from the $\mathrm{Cr}^{1+}$ complex and this reaction occurs via a dominant pathway involving a series of $\mathrm{Cr}^{1+}$ intermediates, including a cis- $\left[\mathrm{Cr}(\mathrm{CO})_{3}\left(\mathrm{Ph}_{2} \mathrm{PN}(\mathrm{i}-\mathrm{Pr}) \mathrm{PPh}_{2}\right)\right]^{+}$ complex and a 'piano-stool' type complex $\left[\mathrm{Cr}(\mathrm{CO})_{2}\left(\mathrm{Ph}_{2} \mathrm{PN}(\mathrm{i}-\mathrm{Pr}) \mathrm{PPh}_{2}\right)\right]^{+}$. Each of these paramagnetic complexes produced a distinctive set of spin Hamiltonian parameters as characterised by CW EPR, and verified by DFT. It was clear that the distribution and nature of the $\mathrm{Cr}^{1+}$ intermediates was highly sensitive to the experimental conditions employed, including the quantity and manner of TEA addition. Hence similar to the case described earlier for the characterisation of the Phillips catalyst, different results can be obtained from different laboratories, if the experimental conditions are not identical. ${ }^{119}$

Owing to the problems associated with using the aluminium based co-catalysts, some work has also been conducted to examine whether UV photolysis can be successfully employed to remove the carbonyl ligands in these catalysts. A CW EPR study was therefore recently reported on the UV activation of a $\left[\mathrm{Cr}(\mathrm{CO})_{4}\left(\mathrm{Ph}_{2} \mathrm{P}\left(\mathrm{CH}_{2}\right)_{3} \mathrm{PPh}_{2}\right)\right]^{+}$complex. ${ }^{120}$ In general there is very little literature on the photochemistry of $\mathrm{Cr}^{1+}$ systems, ${ }^{120}$ despite the copious amount of literature available on the analogous $\mathrm{Cr}^{0}$ complexes; this is likely due to the air sensitive nature of the $\mathrm{Cr}^{1+}$ systems. UV photolysis of the $\left[\mathrm{Cr}(\mathrm{CO})_{4}\left(\mathrm{Ph}_{2} \mathrm{P}\left(\mathrm{CH}_{2}\right)_{3} \mathrm{PPh}_{2}\right)\right]^{+}$complex breaks both the $\mathrm{Cr}-\mathrm{CO}$ and $\mathrm{Cr}-\mathrm{P}$ bonds, ultimately leading to the formation of a 
dicarbonyl $\left[\mathrm{Cr}(\mathrm{CO})_{2}\left(\mathrm{Ph}_{2} \mathrm{P}\left(\mathrm{CH}_{2}\right)_{3} \mathrm{PPh}_{2}\right)_{2}\right]^{+}$complex and a mer- $\left[\mathrm{Cr}(\mathrm{CO})_{3}{ }^{-}\right.$ $\left.\left(\mathrm{Ph}_{2} \mathrm{P}\left(\mathrm{CH}_{2}\right)_{3} \mathrm{PPh}_{2}\right)_{2}\right]^{+}$complex which is an intermediate observed only at low temperature. The spatial symmetry of the starting complex $\left(g_{1}=1.988, g_{2}=2.066, g_{3}=2.066\right)$ and the final complex $\left(g_{1}=1.968\right.$, $\left.g_{2}=2.024, g_{3}=2.024\right)$ were both axial, while the intermediate complex was rhombic $\left(g_{1}=1.984, g_{2}=2.026, g_{3}=2.050\right)$, bearing a non-chelating $\mathrm{P}$ atom. The ability to monitor symmetry changes can be invaluable in the study of reaction intermediates and isomerisation studies.

\section{Microporous systems}

Catalysis by microporous systems such as activated carbons, zeolites, metal organic frameworks and alumina phosphates is very widespread with industrially relevant processes including fossil fuel refining and the production of valuable chemicals. ${ }^{121}$ One of the most important features of these catalysts lies in their crystalline structure. The presence of pores and channels of molecular dimensions can provide some degree of shape selectivity of reactants, intermediates and products within the framework. ${ }^{122}$ Moreover, the large internal surface area and void volumes provide the perfect environment for the coordination of active transition metal centers, which are usually the main actors of the catalytic cycle. The high dispersion of the sites makes the microporous materials suitable as single-site catalysts, capable of filling the gap between homogenous and heterogeneous catalytic science. ${ }^{123}$

EPR spectroscopy has been widely used to investigate catalytically active microporous systems. ${ }^{124,125}$ In most cases, the active species is a transition metal ion in a paramagnetic valence state, associated with the microporous framework. CW and pulse EPR experiments provide a detailed description on the electronic state of the active sites and their surrounding environment. This exquisite information, when combined with data from other techniques, can enable one to determine the location and geometry of the active site, which is fundamental for a better understanding of the catalytic process. Furthermore, owing to the high sensitivity of the technique, the EPR signal can provide quantitative information on the amount of paramagnetic species present in the microporous material, even at very low concentrations.

Although EPR spectroscopy can only detect species bearing unpaired electrons, valuable insights into the geometry, accessibility and reactivity of diamagnetic centres may be indirectly probed using suitable paramagnetic spin probes, that fit into the framework and interact with the species of interest. Such paramagnetic spin probes that have been successfully exploited in studies of microporous materials include nitroxides, ${ }^{126}$ nitric oxide $(\mathrm{NO})^{127,128}$ and superoxide $\left(\mathrm{O}_{2}{ }^{-}\right) \cdot{ }^{129}$ It should also be mentioned that the advent of in situ and operando techniques has provided another opportunity to monitor the catalytically relevant species in microporous materials under nominally active conditions, including the identification of transient radical intermediates and the analysis of photocatalytic efficiency, via light illumination and electrocatalytic performance. ${ }^{130,131}$ This also provides further insights and clarity into the 
reaction mechanisms that can lead to improved catalyst design. ${ }^{132}$ Nonetheless, the intrinsic practical difficulties of in situ methods have limited its approach to CW EPR measurements; pulse EPR has still not been employed for the study of microporous catalysts in reactive estate under such in situ conditions. ${ }^{125}$ In this section of the Chapter, we will present some of the most important examples pertaining to the applications of EPR in the study of microporous single-site catalysis. In particular, we will focus on two of the most representative classes of these materials, namely Zeolites and Metal Organic Frameworks (MOFs). The former class represent the largest group of microporous materials, and are indeed the most widely exploited from an industrial perspective for more than 40 years. ${ }^{133}$ The latter class have recently been introduced into the catalysis field due to their high degree of flexibility, functionality and hydrothermal stability for organic and inorganic components. ${ }^{134}$

\subsection{Zeolites}

Zeolites and zeotype materials are aluminosilicate, aluminophosphate and silico-alumino-phosphate microporous systems characterized by a regular three-dimensional framework of channels and cages. ${ }^{135}$ The fundamental building unit of all zeolites is the tetrahedral site (T site) usually composed by a $\mathrm{Si}^{4+}$ atom coordinated to four oxygen atoms. The $\mathrm{T}$ sites are commonly substituted by $\mathrm{Al}^{3+}, \mathrm{P}^{5+}, \mathrm{Ga}^{3+}$ or even a small number of transition metal ions. The tetrahedral units are connected to each other through the oxygen atoms, and are able to arrange themselves in different ways, to create a huge variety of structures with different framework topologies. Typically, the $\mathrm{Al}$ atoms substitute the siliceous positions and generate an anionic charge inside the solid which has to be compensated by extra-framework cations. In natural zeolites, these are usually alkali or alkaline-earth ions which occupy the microporous space. Since they are not covalently bound to the framework, the charge-balancing cations can be partially or totally exchanged by other different cations.

Whereas the acidic properties of synthetic zeolites have been exploited since the 1960s on large industrial scales, for example in crude oil refining, ${ }^{136}$ the interest in transition metal ion (TMIs) exchanged zeolites and zeotypes as redox catalyst has grown over the past 20 years. The introduction of $\mathrm{Co}, \mathrm{Cu}, \mathrm{Fe}, \mathrm{Ti}, \mathrm{Ni}, \mathrm{Rh}$ and $\mathrm{Pd}$ as counterions inside the zeolitic framework has proven to be very promising in industrially relevant oxidation and reduction reactions. ${ }^{137,138}$ As most of these TMIs are paramagnetic, EPR spectroscopy has been extensively used in the characterisation of such exchanged zeolites for several decades. ${ }^{132}$ On the one hand, it is a powerful tool enabling the user to extract information on the location, structure and dispersion of the paramagnetic TMIs in zeolite catalysts. On the other hand, thanks to recent technological advances, the application of in situ investigations has also made it possible to monitor catalytically active species under conditions close to those of the operating reaction conditions. ${ }^{139,140}$

Perhaps on the of the most widely studied paramagnetic TMI in exchanged zeolites has been $\mathrm{Cu}^{2+}$, and numerous EPR studies have been 
devoted to this over the years. ${ }^{141}$ The identification of the local environment around the $\mathrm{Cu}^{2+}$ exchanged sites is an important prerequisite for understanding their catalytic activity. Normally, for a particular zeolite, more than one copper species coexists in the material, depending on the hydration state and $\mathrm{Si} / \mathrm{Al}$ ratio. After the removal of water, the $\mathrm{Cu}^{2+}$ ions are strongly bound to the oxygens of the framework and the difference among the sites are mainly related to the Al distributions. ${ }^{142}$ The presence of $\mathrm{Al}$ pairs, as opposed to isolated $\mathrm{Al}$ sites around the cupric species, affect the redox and/or acidic properties for a specific $\mathrm{Cu}$ site and, thus, the activity of the catalyst. ${ }^{143}$

The hyperfine coupling constants and $g$ values directly obtained from the CW EPR spectrum are strongly affected by the local environment for a specific copper ion. ${ }^{144}$ In fact, for a given coordination sphere, the $\mathrm{Cu}^{2+}$ complex, which suffers from a lower ligand field splitting parameter $\left(\Delta_{L F}\right)$ and less negative total charge on the copper, will also produce higher $g_{\|}$and lower $A_{\|}$values. ${ }^{145}$ The pioneering work of Peisach and Blumberg demonstrated this empirical correlation between the EPR parameters for several $\mathrm{Cu}^{2+}$ containing biological systems. ${ }^{146}$ Later on, these models were successfully used for the interpretation of copper exchanged zeolites ${ }^{139}$ (Fig. 6).

An example of how these plots can be interpreted is given in Fig. 6. All of the dehydrated zeolites are almost perfectly located on the antidiagonal of the plot. This means that generally, for the same coordinating atom type and number (e.g. 4 equatorial oxygen donor atoms), a $\mathrm{Cu}^{2+}$ ion surrounded by a more negative coordination sphere is found in the upper-left part of the plot, whereas in the opposite case, it is found in the lower-right. Thus, the information extracted from the Peisach-Blumberg model is fundamental for the assignment and understanding of the $\mathrm{Cu}^{2+}$ sites. For instance, Cu-MFI hosts two distinct copper species named as MF1 and MF2 in Fig. 6. MF2 was assigned to a six-membered ring site with two Al whereas MFI1 was assigned to a six-membered ring site in which one $\mathrm{Al}$ is inside the ring while the other one bridges the ring. ${ }^{139}$ Since the latter

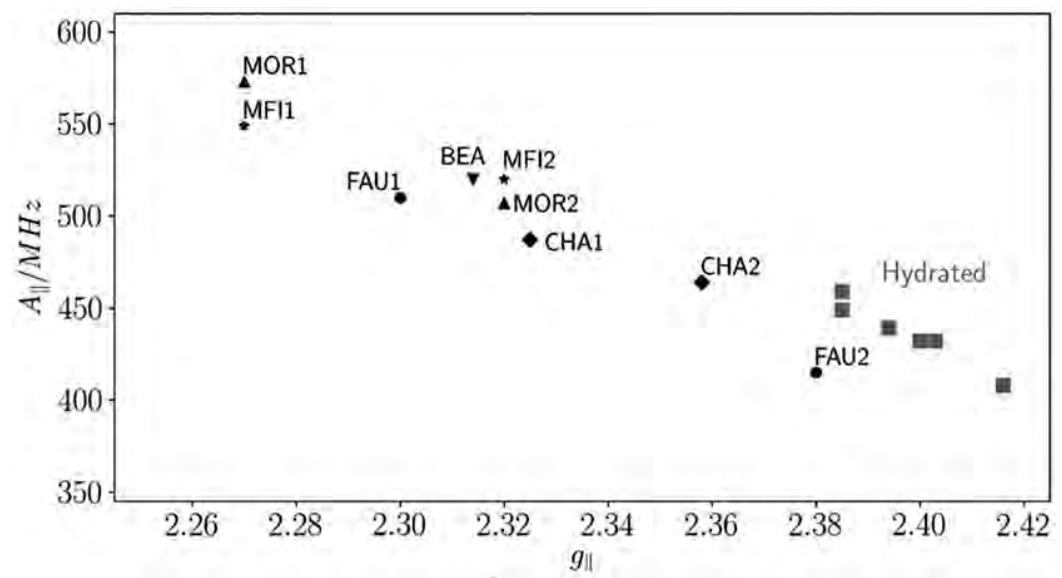

Fig. 6 Peisach-Blumberg plot for different $\mathrm{Cu}$-exchanged zeolites. The data for hydrated $\mathrm{Cu}$ zeolites are given with squares and they refer to low temperature measurements. Adapted from ref. 144 with permission from Springer Nature, Copyright 2016. 
environment produces a more negative charge on the $\mathrm{Cu}^{2+}$ ion, the parameters related to this site appear in the higher left hand part of the plot. Regarding the hydrated Cu-zeolites, their position on the bottom right hand side is due to the different number and nature of ligands around the copper (i.e., water molecules instead of framework atoms).

Despite the enormous potential offered by in situ EPR spectroscopy, ${ }^{147}$ many limitations and difficulties remain. The advent of specific experimental assembles/setups has facilitated some limited exploitation of the approach to study zeolite catalysts under almost operando conditions. Examples include the analysis of TMIs in zeolites after adsorption of different reactants or probe molecules, ${ }^{148}$ after treatment at temperatures or pressures typical of a specific reaction, ${ }^{149}$ or for the identification of radical intermediates. ${ }^{150}$ Of particular note is the work by Brückner et al., ${ }^{150}$ on Fe-ZSM-5 zeolites. It was found that these catalysts are able to oxidise benzene to phenol in the presence of $\mathrm{N}_{2} \mathrm{O}$ at room temperature. $^{151}$ The active species responsible for the oxidation process was attributed to a so-called $\alpha$-oxygen species, formed on the iron sites of the ZSM-5 material after contact with $\mathrm{N}_{2} \mathrm{O}$. The radical anionic nature of the $\alpha$-oxygen was experimentally confirmed by in situ EPR results. After a pre-treatment of Fe-ZSM-5 at $973 \mathrm{~K}$ in Ar, the $\mathrm{Fe}^{3+}$ single site EPR signal disappeared because of the reduction to $\mathrm{Fe}^{2+}$, which is effectively EPR silent at conventional microwave frequencies. The subsequent oxidation at $523 \mathrm{~K}$ in an $\mathrm{N}_{2} \mathrm{O} / \mathrm{Ar}$ flow regenerated the iron signal, together with a radical line at $g=2.018$. This signal was assigned to an $\mathrm{O}^{\bullet-}$ radical anion, formed by electron transfer from $\mathrm{Fe}^{2+}$ to $\mathrm{N}_{2} \mathrm{O} .{ }^{150}$ It was also proved that only $\mathrm{N}_{2} \mathrm{O}$ is able to create the $\alpha$-oxygen centre because no radical line was observed when $\mathrm{O}_{2}$ was used as oxidant.

It is certainly clear that EPR spectroscopy is a powerful technique for providing a detailed and informative description on the active sites of TMI exchanged zeolites, including geometry and electronic structural data. Moreover, the application of in situ EPR approaches allows one to monitor fundamental changes to the nature of the catalytically TMI sites, under operative conditions and/or identify specific radical species formed from certain reactants.

\subsection{Metal organic frameworks}

In recent years, Metal Organic Frameworks (MOFs) have started to gain considerable attention as the most prominent class of microporous materials for applications in gas storage and separation, liquid purification, catalysis, sensing, electrochemical energy, super-capacitors, and heat storage owing to their unique structural diversity and tunability. ${ }^{152-157}$ The ultrahigh porosity, tuneable pore nature, enormous internal surface $\left(1000-10000 \mathrm{~m}^{2} \mathrm{~g}^{-1}\right)$ and volume area, very low density and crystal integrity are just some of the bespoke properties of MOFs which provide a pathway towards a potentially unique role in the field of heterogeneous catalysis. ${ }^{153-155}$ The high surface area of MOFs also creates large accessible volume space with a large number and variety of active sites for catalysis. ${ }^{153}$ In addition to this, another important property of MOFs is the so-called 
'breathing effect', where the porous nature of the MOF can be manipulated to reversibly change from narrow to large pore transformations without any topological framework distortion. ${ }^{157}$ Furthermore, MOF materials can also be functionalised for bespoke catalytic applications via the modification of coordinatively unsaturated active sites, the encapsulation of guest species in pores, or by coating with functional materials. ${ }^{153,158,159}$

Although MOFs are essentially based on a cage-like complex structure, they are composed of two simple hybrid building blocks through ion-covalent bonds. The first is the metal clusters, or secondary building units (SBU), and the second is the organic linkers. ${ }^{154,157,160}$ The appropriate choice of MOF components dictate the physical and chemical properties of the resulting material, including porosity, chemical and thermal stability, magnetic susceptibility, conductivity, etc. $^{154,157,160}$ The first MOF, developed by Yaghi et al., ${ }^{161}$ was namely MOF-5 with a relatively simple structure. Later developments expanded the complexity of the chemical composition, to include more than one linker and/or hetero bimetallic species using a variety of synthesis techniques including hydrothermal, solvothermal, electrochemical, mechanochemical, sonochemical, and microwave assisted techniques, along with other post-synthesis modification methods adopted by several groups. ${ }^{160,162}$ Furthermore, chemists have also successfully synthesised highly complex and interesting multi-component MOFs which contain multiple SBU and organic linkers within a single framework. ${ }^{162}$

Once again, owing to the likely presence of paramagnetic centres in these MOFs, unsurprisingly EPR has played an important role in the characterisation of such materials (as summarised in Fig. 7). Most notably, Kultaeva et al., ${ }^{163}$ correlated the magnetic properties of a copper-based MOF, labelled $[\mathrm{Cu}($ prz-trz-ia)], through the temperature-dependent magnetisation results of SQUID magnetometry along with multi-frequency EPR results. It is interesting to note that, the temperature-dependent magnetic

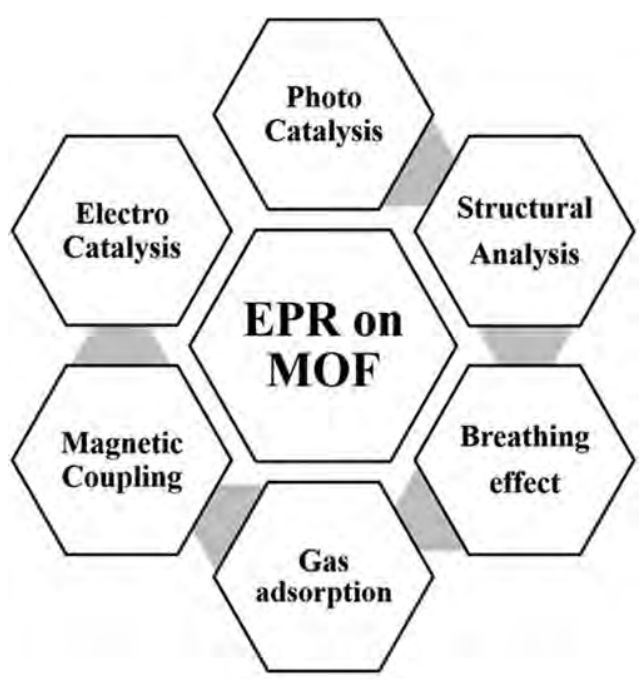

Fig. 7 EPR as a tool to study different properties of MOFs. 
behaviour extracted from the EPR results and the magnetic susceptibility data from the SQUID experiments provided a negative value of the paramagnetic Curie temperature $\left(\theta_{\mathrm{p}}\right)$ due to the antiferromagnetic interaction between the cupric ions. An isotropic exchange coupling constant, $J_{1}$, of antiferromagnetically coupled cupric ions was extracted from the SQUID $\left(-26 \mathrm{~cm}^{-1}\right)$ and EPR $\left( \pm 23 \mathrm{~cm}^{-1}\right)$ results, which agreed well with the DFT calculations.

Recently, Bitzer et al., ${ }^{164}$ used EPR along with the X-ray diffraction and X-ray absorption spectroscopy to study the incorporation of $\mathrm{Fe}^{3+}$ ions into another copper-based MOF, labelled CuBTC, with paddlewheel units. The presence of $\mathrm{Fe}^{3+}-\mathrm{Cu}^{2+}$ paddlewheels have been successfully confirmed from the strong magnetic interactions among the $\mathrm{Cu}^{2+}-\mathrm{Fe}^{3+}$ species with a $g$ value of 2.023. Using a variety of EPR methods, Mendt et al., ${ }^{165-167}$ also explored the structural phase transition of MIL-53(Al/Cr), ${ }^{165}$ adsorption of $\mathrm{CO}_{2}$ over the $\mathrm{MIL}-53(\mathrm{Al} / \mathrm{Cr})^{166}$ under pressure, and the low temperature NO binding in the MIL-100(Al). ${ }^{167}$

Although several excellent literature reviews and papers have been published that deal with the catalytic applications of MOF for a varied host of reactions, ${ }^{153,160,168,169}$ and whilst many EPR publications have focused on heterogeneous catalysis, ${ }^{90,170}$ there are fewer articles devoted to the combined EPR study of catalytic applications in MOFs. Currently, EPR is finding considerable success in the studies of charge generation, pathways to charge transfer, broad band absorption in photocatalytic activity, and mechanistic origins of electrocatalysts in MOF materials. For example, Nasalevich et al., ${ }^{131}$ investigated the photocatalytic potential of $\mathrm{NH}_{2}$ functionalized, $d^{0}$ metal based MIL-125(Ti), UiO-66(Zr) and UiO-66(Hf) MOFs through X-band EPR under UV illumination. The $\mathrm{Ti}^{3+}(S=1 / 2)$ ions were generated in the photoexcited state, only in the $\mathrm{NH}_{2}-\mathrm{MIL}-125(\mathrm{Ti})$ material upon UV illumination as a result of ligand-metal charge transfer(LCMT). Also, a transient weak signal found in the $\mathrm{NH}_{2}-\mathrm{UiO}-66(\mathrm{Zr})$ and $\mathrm{NH}_{2}$-UiO66(Hf) materials, was attributed to the highest occupied crystalline orbital (HOCO) - lowest unoccupied crystalline orbital (LUCO) transition of a radical in the framework and no LCMT was observed. The EPR results were also in accordance with the computational results. Horiuchi et al. ${ }^{171}$ also performed X-band in situ EPR studies on amino functionalised Ti-MOF under the visible light irradiation. Once again, paramagnetic $\mathrm{Ti}^{3+}$ ions were produced from the diamagnetic $\mathrm{Ti}^{4+}$ centres via LCMT with reported spin Hamiltonian parameters $g_{x x}=1.980, g_{y y}=1.953, g_{z z}=1.889$. The presence of $\mathrm{Ti}^{3+}$ ions was confirmed by exposure of the material to air, at which point the paramagnetic $\mathrm{Ti}^{3+}$ centres were immediately oxidised back to the original $\mathrm{Ti}^{4+}$ centres.

In another study, Chen et al., ${ }^{130}$ investigated the NNU-28(Zr) MOF under the continuous visible light illumination using in situ X-band EPR to study the photocatalytic activity of $\mathrm{CO}_{2}$ reduction with formate formation. Firstly, the anthracene-based ligand in the NNU-28 material was found to act as a photo-reducing component of $\mathrm{CO}_{2}$, which was confirmed by the strong EPR signal of an anionic radical $(g=2.003)$ under visible light irradiation, whereas the ligand itself in the absence of any irradiation, gave a weak signal with the same $g$ value. The authors found two more 
additional signals at $g=2.009$ and $g=2.030$ during the in situ EPR measurements of NNU-28(Zr) upon continuous visible light illumination, which were not related to the ligand. These new signals were attributed to the LCMT process of $\mathrm{Zr}_{6}$ oxo clusters, thereby revealing the existence of a dual catalytic pathway as confirmed by the EPR. Zhao et al., ${ }^{172}$ investigated the electrocatalytic performance of mixed $\mathrm{CO}_{0.6} \mathrm{Fe}_{0.4}-\mathrm{MOF}-74$ and compared their results with Co-MOF-74 $\left(\mathrm{Co}^{2+}, S=3 / 2\right)$ and Fe-MOF-74 $\left(\mathrm{Fe}^{2+}\right.$, $S=2$ ) materials for the oxygen evolution reaction (OER) by means of X-band EPR. The EPR data revealed that the $\mathrm{Co}_{0.6} \mathrm{Fe}_{0.4}-\mathrm{MOF}-74$ has more open metal clusters compared to the single metal counterparts. Ji et al. ${ }^{173}$ have also investigated the Lewis acidic nature of MOFs, including $\mathrm{ZrOH}-$ BTC and ZrOTf-BTC, to better understand the catalytic performance of the materials. The difference between the $g_{\mathrm{zz}}$ values from the $\mathrm{Zr}\left(\mathrm{O}^{\bullet-}\right)$ active species of ZrOH-BTC and ZrOTf-BTC, was revealed by EPR owing to the difference in Lewis acidity of those MOFs. The $g_{z z}$ value of 2.0310 for ZrOTf-BTC was shown to arise from the energy splitting $(\Delta E=0.99 \mathrm{eV})$ between the $\pi_{x}^{*}$ and $\pi_{y}{ }^{*}$ orbitals which is comparable to the $\Delta E(1 \mathrm{eV})$ of benchmark homogeneous Lewis acid catalyst $\mathrm{Sc}(\mathrm{OTf})_{3}$.

\section{Homogeneous systems for small molecule activation}

Homogeneous photocatalysis is a fertile field of research that is gathering more and more momentum in the chemical research world. This is because activation via light irradiation gives access to many different reaction pathways, which are sometimes difficult to achieve via other more conventional synthetic methods, and usually with high selectivity for the products. ${ }^{174}$ Most of these characteristics are due to the transient nature of the active forms involved in these reactions, as the irradiation of the chromophores generates high-energy species, such as ionic radicals and excited states, which differ greatly in their capabilities from their precursors. ${ }^{175}$ This of course presents a significant obstacle in determining the nature of these intermediate species, as their high reactivity often comes at the cost of the overall lifetime of the compound. Consequently, understanding the mechanism of reaction for this type of process is quite challenging.

Catalysis is known for its crucial role in the modern chemical industry, and due to the progressive tendency to eliminate expensive and toxic noble metals, in favour of the more abundant and less toxic first-row transition metals, the analysis and interests in open-shell (radical type, paramagnetic) complexes is growing significantly. ${ }^{176}$ Indeed, the efficiency of the platinum group metals (PGMs) is unsurpassed compared to the first-row transition metals; nevertheless, this has not deterred many international research groups in actively exploring new ways to exploit these latter metals, to deliver reactions akin to enzyme based systems. For example, the oxidation of alcohols to aldehydes, ketones, and carboxylic acids is perhaps one of the most widely used class of oxidation reactions in organic chemistry, and homogeneous palladium-catalysed systems are very effective for these selective oxidation of organic molecules primarily based on the two-electron redox reactions. ${ }^{177}$ However, 
more recently, copper catalysts have demonstrated some potential in these types of reactions. Copper is highly desirable for such reactions as it is far cheaper, and less toxic, compared to palladium. Indeed, $\mathrm{Cu}-$ containing enzymes (oxidases) can mediate a wide variety of essential oxidation reactions in nature, from outer-sphere electron transfers (e.g., laccases) to dehydrogenation (e.g., galactose oxidase). ${ }^{178}$ So the potential opportunities for using homogeneous $\mathrm{Cu}$-based catalysts is obvious, and whilst they have been successfully applied to numerous aerobic oxidation reactions, ${ }^{179-181}$ the mechanism by which these $\mathrm{Cu}$-mediated reactions operate are not well understood, unlike the PGM counterparts. ${ }^{177}$

The activation of so-called inert bonds like carbon-carbon $(\mathrm{C}-\mathrm{C})$ bonds is another reaction of extreme importance in organic chemistry. In conventional organic transformations, relatively inert $\mathrm{C}-\mathrm{H}, \mathrm{C}-\mathrm{O}$ and $\mathrm{C}-\mathrm{C}$ bonds must be altered to the analogous activated $\mathrm{C}-\mathrm{X}(\mathrm{X}=\mathrm{I}, \mathrm{Br}, \mathrm{Cl})$ or $\mathrm{C}-\mathrm{OR}$ functionalities, which involve more elaborate synthetic routes and invariably result in the generation of by-products. Therefore, in modern chemistry, transition metal catalysed highly selective $\mathrm{C}-\mathrm{H}, \mathrm{C}-\mathrm{O}$, and $\mathrm{C}-\mathrm{C}$ functionalisation is also growing in momentum. ${ }^{182}$ Despite the prosperous advances made in transition metal catalytic and photocatalytic methodologies, there is still a lack of understanding on how these catalysts operate, and as paramagnetic species are frequently involved, the traditional analytical tool of synthetic chemists, NMR, cannot be easily applied. For this reason, EPR is essential when probing the single electron transfer events typical of first-row transition metals. The paramagnetic pre-catalyst, the activated catalyst itself, or the subsequent reactive intermediates, can all be investigated for valuable insights into the formal oxidation state of the metal and the effect of ligand structure on the catalytic activity. ${ }^{183}$

\subsection{Homogeneous photocatalytic centres}

EPR has been widely used to understand the mechanism of heterogeneous photochemical systems. ${ }^{184-186}$ However, the use of EPR to study homogeneous photocatalysis is still comparatively sparse. The most commonly employed transition metal catalysts used in homogeneous photocatalysis are based on ruthenium and iridium. ${ }^{175}$ The $\left[\mathrm{Ru}(\mathrm{bpy})_{3}\right]^{2+}$ (bpy $=2,2^{\prime}$-bipyridine) complex, in particular, is an extremely popular sensitiser and has been extensively studied and employed as a means to harness light energy. ${ }^{187}$ The ground state of the complex is EPR silent, although most of the photoinduced excited states are not. Wang et al., ${ }^{187}$ for instance, reported how this ruthenium complex can be used to promote a light-driven water oxidation by a di-nuclear cobalt complex, $\left[(\mathrm{TPA}) \mathrm{Co}(\mu-\mathrm{OH})\left(\mu-\mathrm{O}_{2}\right) \mathrm{Co}(\mathrm{TPA})\right]\left(\mathrm{ClO}_{4}\right)_{3} \cdot{ }^{188}$ In the presence of an electron acceptor, $\mathrm{Na}_{2}\left(\mathrm{~S}_{2} \mathrm{O}_{8}\right)$, and at a $\mathrm{pH}$ maintained at 8 via a borate buffer, this system revealed the evolution of oxygen at a turnover frequency of 1.4. X-band CW EPR at low temperature (10 K) was then used to follow the evolution of the system after irradiation; while the initial mixture is EPR silent, as the $\mathrm{Co}^{3+} / \mathrm{Co}^{3+}$ complex does not possess any unpaired electrons, after a single laser flash at $532 \mathrm{~nm}$ the system developed a signal with $g=2.03$ which is consistent with a mixed valence $S=1 / 2$ di-nuclear $\mathrm{Co}^{3+} / \mathrm{Co}^{4+}$ state. ${ }^{189,190}$ Further irradiation resulted in a gradual decrease 
in the intensity of this signal, and eventually the appearance of a broad spectral feature, composed of many different signals between 250 and $295 \mathrm{mT}$. The two main signals appear to be characterised with $g$ values of 2.33 and 2.42 respectively. The signals with $g \approx 2.3$ have been reported to be evidence for $[\mathrm{Co}(\mathrm{Iv})(\mathrm{O})]$ species in cobalt oxide films. ${ }^{191}$ Since lightscattering experiments eliminated the possibility that the complex degrades into nanoparticles during the process, the first signal was suggestive of a $\mathrm{Co}^{4+}(\mathrm{O}) / \mathrm{Co}^{4+}(\mathrm{O})$ complex, but the low intensity makes a definitive assignation of the signal rather difficult. Based on these observations, the proposed mechanism showed that evolution of the complex between different di-nuclear structures with the two metallic centres progresses between oxidation states.

The time evolution of the paramagnetic species can also reveal interesting information. Hollmann et al., ${ }^{191,192}$ carried out in situ EPR measurements to gain mechanistic insight into a novel photocatalytic system, ${ }^{192,193}$ employing an iridium complex $\left[\operatorname{Ir}(\mathrm{ppy})_{2}(\mathrm{bpy})\right]^{+}(\mathrm{ppy}=2$ phenylpyridine), as a photosensitiser for the water-reduction catalyst $\left[\mathrm{Fe}_{3}(\mathrm{CO})_{12}\right]$, along with triethylamine as a sacrificial reductant for the chromophore. The first step of the reaction is the excitation of the photosensitiser and its subsequent quenching by triethylamine, which generates the reduced form of the iridium compound. The $\left[\operatorname{Ir}(\mathrm{ppy})_{2}(\mathrm{bpy})\right]^{+}$ complex is a low spin $d^{6}$ species and therefore EPR silent. However, after irradiation at $300 \mathrm{~K}$ in the presence of the reducing agent, the formation of the reduced species gives rise to an intense isotropic signal at $g=1.984$. The absence of such a signal in the pure solvent (tetrahydrofuran), or in a mixture of the solvent and water, suggests that the irradiation and the sacrificial reductant are both necessary to initiate the reaction. After reaching a maximum intensity after 20 minutes of irradiation, the signal rapidly decreased due to the degradation of the ligands. The reduced form of the iridium complex then reacted with the iron pre-catalyst, to form the active species of the water-reduction cycle, which generated hydrogen from the water protons. The only intermediate that had been previously detected was $\left[\mathrm{HFe}_{3}(\mathrm{CO})_{11}\right]^{-}$, which was presumed to be the active catalytic species. ${ }^{194}$ When the full reaction mixture, including the iron catalyst, was analysed using EPR, the iridium signal was not observed, due to the fast electron transfer to $\left[\mathrm{Fe}_{3}(\mathrm{CO})_{12}\right]$ that greatly reduced the reduced photosensitiser lifetime.

The second catalytic cycle was more difficult to observe via EPR, due to the prevalence of EPR silent species. After addition of the iridium photosensitiser, a non-irradiated sample displayed three narrow radical signals. Each one of these signals was assigned to a specific di-nuclear iron radical complex, $\left[\mathrm{Fe}_{3}(\mathrm{CO})_{12}\right]^{\bullet-}(g=2.0016), \quad\left[\mathrm{Fe}_{3}(\mathrm{CO})_{11}\right]^{\bullet-}$ $(g=2.0497)$, and $\left[\mathrm{Fe}_{2}(\mathrm{CO})_{8}\right]^{--}(g=2.0385)$, which accounted for about $94 \%$ of the all iron present in the starting solution. After irradiation these signals were replaced by a triplet signal with $g=2.0433$ consistent with the formation of a $\left[\mathrm{H}_{2} \mathrm{Fe}_{2}(\mathrm{CO})_{7}\right]^{\bullet-}$ species, accounting for just $3 \%$ of the total iron content. Experiments conducted with a $420 \mathrm{~nm}$ cut-off filter, which excludes the UV component of the irradiating light, showed a nearcomplete suppression of these radical signals without a corresponding 
reduction of hydrogen production, proving that these species are decomposition products, and are not involved in the reaction mechanism. The low intensity of the EPR signals in these reactions suggest that the main species involved are diamagnetic. This observation was confirmed by in-situ Raman spectroscopy and DFT calculations, suggesting the $\left[\mathrm{HFe}_{3}(\mathrm{CO})_{11}\right]^{-}$species is the main component present during the reaction, demonstrating the importance of a combining a variety of characterisation techniques in order to achieve a comprehensive approach to mechanistic investigations.

An important tendency in the current research on photochemical systems is the shift towards earth-abundant metals and organic dyes, which would greatly increase the practicality and the green potential of the photochemical processes. ${ }^{195}$ Ruthenium and iridium, while well-known and extensively studied, are rare metals, and as such are severely limited in their application. As an example, several noble-metal free alternatives have been studied as photosensitisers for the previously cited iron-based waterreducing carbonyl complex, such as copper(I) complexes, zinc porphyrins and organic dyes. ${ }^{196-198}$ Many of these catalytic cycles involve radicals with very short lifetimes, which require the use of radical traps for detection, thus adding another layer of complexity to the study. ${ }^{199}$ Thorough EPR investigations of these systems is often further complicated by poorly understood reactivities and detection issues. For example, copper (I) based complexes, such as $\left[\mathrm{Cu}(\mathrm{dap})_{2}\right]^{+}(\mathrm{dap}=2,9$-bis( $p$-anisyl)-1,10-phenanthroline), have been successfully employed in a wide variety of photoredox reactions. ${ }^{200-203}$ As copper-based photocatalytic processes are relatively new, these systems have seldom been subjected to detailed mechanistic analyses. EPR could offer a promising avenue of research in this field, since the complex should evolve to a $\mathrm{Cu}^{2+}$ site at some point during the catalytic cycle. $^{204,205}$ Furthermore, complexes presenting $\mathrm{M}-\mathrm{N}$ bonds, such as metal porphyrins, have also been successfully investigated using pulsed EPR techniques, such as ESEEM and HYSCORE, revealing detailed structural information on the system. ${ }^{206,207}$ Thus, despite the obvious challenges, it is easy to see how these methodologies could be fruitfully adapted to this, and other novel photocatalytic systems, in order to obtain more important mechanistic insights and further expand this field of research.

\subsection{Catalytic alcohol oxidation}

The catalytic oxidation of alcohols is a very important industrial process, and the reaction mechanism is often dominated by the involvement of free radicals and paramagnetic transition metal species. Understanding the nature of these intermediates is therefore essential in order to ascertain the underlying catalytic cycle, and as illustrated earlier for other important reactions, EPR provides an ideal method of choice to unravel the crucial low energy reaction pathways provided by the catalyst. ${ }^{183}$ Considering the dominance of paramagnetic species in copper-containing alcohol oxidation catalysts, Stahl et al., recently explored the mechanism of aerobic alcohol oxidation with $\mathrm{Cu} /$ nitroxyl systems. ${ }^{208-211}$ In a series of studies, the authors evaluated the performance of various $\mathrm{Cu} /$ nitroxyl catalytic systems containing $\mathrm{Cu} / \mathrm{TEMPO}$ (where TEMPO $=2,2,6,6$-tetramethylpiperidine- $N$-oxyl) 
and $\mathrm{Cu} / \mathrm{DBED}, \mathrm{DMAP}$ (where $\mathrm{DBED}=N$ - $N^{\prime}$-di-tert-butylendiamine, and DMAP $=p$-(N,N-dimethylamino $)$ pyridine $).{ }^{210,212}$ Combined EPR, UV-vis and cyclic voltammetry (CV) indicated a two-stage catalytic mechanism involving catalyst oxidation, in which $\mathrm{Cu}^{1+}$ and TEMPO-H are react with $\mathrm{O}_{2}$ and substrate oxidation, mediated by $\mathrm{Cu}^{2+}$ and the nitroxyl radical via a $\mathrm{Cu}^{2+}$-alkoxide intermediate. ${ }^{210}$ Since the research was based on the comparison of both aliphatic and aromatic alcohols, interestingly, the observations suggested that the resting state of the catalyst varied depending on the identity of alcohol substrate. With aromatic alcohols such as ph- $\mathrm{CH}_{2} \mathrm{OH}$, EPR revealed that the majority of the catalyst is present as $\mathrm{Cu}^{1+}$, whereas with an aliphatic substrate like $\mathrm{Cy}-\mathrm{CH}_{2} \mathrm{OH}$, both $\mathrm{Cu}^{1+}$ and $\mathrm{Cu}^{2+}$ co-exist during the reaction and their ratios change as the substrate oxidation progresses.

Another related homogenous catalyst system entailing $\left[\mathrm{Cu}(\mathrm{MeCN})_{4}\right] \mathrm{PF}_{6}$, $N$ - $N^{\prime}$-di-tert-butylendiamine (DBED) and $\mathrm{p}$-( $N, N$-dimethylamino)pyridine (DMAP) was shown to be capable of mediating efficient aerobic oxidation of alcohols. ${ }^{212}$ This catalytic system was correlated with an oxidative self-processing step and EPR spectroscopy evidenced the build-up of organic nitroxyl species which could be generated during steady-state turnover, from DBED with the EPR signal of an organic radical $g=2.0023$ clearly visible, accompanied by a hyperfine coupling of $A=85 \mathrm{MHz}$. The signal increased in intensity during the steady-state period of the reaction, and was assigned to the EPR spectra of the nitroxyl radical TEMPO and (9-azobicyclo[3.3.1]nonane $N$-oxyl) ABNO. ${ }^{213,214}$ Analysis of the extracted aliquots of the Cu/DBED/DMAP catalyst system revealed an EPR spectrum with axial symmetry based on the parameters $g_{\|}>g_{\perp}, g_{x x}=2.03, g_{y y}=2.07, g_{z z}=2.26$ and $A_{\|}=553 \mathrm{MHz}$.

Both galactose oxidase (GAO) and $\mathrm{Cu}$ /nitroxyl systems have been well investigated and different catalytic pathways have been proposed based on EPR spectroscopy, kinetic analyses and computational studies. Concurrently in both oxidation methods, the formation of $\mathrm{Cu}^{2+}$-alkoxide intermediates has been confirmed in several cases. ${ }^{215,216}$ In an effort to understand the structure of the intermediates, Stoll et al., prepared a $\mathrm{Cu}^{\mathrm{II}}$ alkoxide complex, labelled $\mathrm{Tp}^{\mathrm{tBu}} \mathrm{Cu}^{\mathrm{II}}\left(\mathrm{OCH}_{2} \mathrm{CF}_{3}\right)$, where $\mathrm{Tp}^{\mathrm{tBu}}=$ hydrotris(3-tert-butyl-pyrazolyl)borate which was abbreviated to $\mathrm{Cu}^{\mathrm{II}}-\mathrm{O}(\mathrm{TFE}){ }^{215}$ The authors characterised the electronic structure of the complex using powder and single crystal EPR, and confirmed the expected trigonal monopyramidal coordination geometry. Their study revealed the identity of single occupied molecular orbital (SOMO) as $\mathrm{d}_{x^{2}-y^{2}}$ and its orientation within the $\mathrm{Cu}^{\mathrm{II}}-\mathrm{O}$ (TFE) complex, in a plane normal to the $Z_{g}$ axis and nearly normal to the long $\mathrm{Cu}-\mathrm{N}_{\text {axial }}$ bond. The compound produced a distinctive EPR spectrum, possessing axial symmetry and large $\Delta g$ shift producing $g_{z z}=2.44$ with a small copper hyperfine coupling of ${ }^{\mathrm{Cu}} A_{z z}=120 \mathrm{MHz} .{ }^{217}$ In addition to probing the interaction of the unpaired electron with copper nuclei, ENDOR measurements were also used to ascertain the magnitude of the interaction between the unpaired electron and nearby spin active nuclei $\left({ }^{1} \mathrm{H},{ }^{19} \mathrm{~F},{ }^{14} \mathrm{~N}\right)$. With these investigations, they quantified the extent of delocalization of the unpaired electron onto the $\mathrm{TP}^{\mathrm{tBu}}$ and triflourethoxide ligands and found much of the spin population 
is based on the $\mathrm{Cu}^{2+}$ ion $(\approx 68 \%)$ with no more than $15 \%$ on the oxygen of the alkoxide ligand.

Bosch et al., explored the electron structure and reactivity of a copper complexes bearing bidentate redox-active ligands consisting of $\mathrm{H}$-bonding donor groups. ${ }^{218}$ A combination of single-crystal X-ray, EPR, UV-vis and CV techniques were combined to probe the catalytic mechanism of this complex, which had some pronounced differences with the common GAO model systems, in which $\mathrm{O}_{2}$ reduction occurs at the same time as oxidation of the substrates. ${ }^{219}$ In their initial study, the molecular structure of the complex was analysed by single-crystal crystallography. This revealed that the molecular structure depended on the coordinating ligand and solvent used in crystallisation, including a square-planar or twisted pseudo-tetrahedral geometry. The redox chemistry of copper complexes was then probed by CV and UV-vis spectroscopy, and the results were corroborated by EPR spectroscopy. The EPR data obtained in these oxidation/reduction experiments confirmed the axial symmetry of the complex, with $g_{\perp}=2.05, g_{\|}=2.21$ and $A_{\|}=154 \mathrm{G}$. The addition of a second equivalent of $\mathrm{Fc}^{+}$generated a copper species which was EPR silent, due to its associated two $o$-benzosemi-quinonediiminato radical ligands, in which the metal ion and the ligand radicals were antiferromagnetically coupled due to the nonplanar geometry (i.e., $D_{2 \mathrm{~d}}$ geometry), and was concomitant with the appearance of an EPR signal at $g=1.99$. Several papers have also been published recently describing the role of EPR to study the catalytic oxidation reactions of various $\mathrm{Cu}$ complexes. ${ }^{220-222}$ In most of these $\mathrm{Cu}^{2+}$ complexes, EPR was primarily used to identify the oxidation state of the central metal ion, the coordination environment surrounding the active site and also to gain insights into the alcohol oxidation mechanism.

\subsection{C-C cross-coupling}

The carbon-carbon cross-coupling reaction is one of the most important chemical transformations in synthetic organic chemistry. Among the transition-metal catalysts employed for this reaction, nickel- and iron-based systems have been very successful in important reactions such as the Heck, Himaya, Kumada, Negishi, Suzuki-Miyaura, Sonogashira and Still coupling reactions. Iron is particularly attractive for these reactions because is is very abundant, and also easily switched among several oxidation states in catalytic cycles. ${ }^{223}$ Different spectroscopic methods, including EPR, ${ }^{57} \mathrm{Fe}$ Mössbauer, and magnetic circular dichroism, have revolutionised the ability to delineate the underlying iron and nickel speciation. ${ }^{224}$ The driving force in this field, in recent years, has focused on the choice of ligands employed to stabilise the active oxidation states, such as $N$-heterocyclic carbenes (NHCs) and bisphosphines, and these ligands have also been found to improve the overall selectivity in cross-coupling reactions. ${ }^{225-228}$

For example, Whittlesey et al., ${ }^{224,228,229}$ designed a series of air-sensitive $\left[\mathrm{Ni}^{\mathrm{I}}\left(\mathrm{PPh}_{3}\right)(\mathrm{NHC}) \mathrm{X}\right]$ complexes $(\mathrm{X}=\mathrm{Br}, \mathrm{Cl})$ using bulky NHC ligands. They investigated the effect of sterically demanding substitution at the central heteroaromatic ring which is required to stabilise the low-coordinate and low-valent $\mathrm{Ni}^{1+}$ complex and to avoid any intermolecular 
reactions. ${ }^{225,229,230}$ The authors used a combination of CW and pulsed EPR spectroscopy, with complimentary DFT calculations, to extract information about the fundamental properties (structure and bonding) and catalytic efficiency of the complex in the Kumada coupling of aryl-flourides and aryl-chlorides. The EPR spectra revealed a rhombic symmetry for the low coordinated $\mathrm{Ni}^{1+}$ systems, with a large super-hyperfine coupling to the ${ }^{31} \mathrm{P}$ and ${ }^{79,81} \mathrm{Br}$ nuclei. All complexes displayed an unusual trend in the $g$ values $\left(g_{3}-g_{2}<g_{2}-g_{1}\right)$ which is in contrast with the observations for other three coordinated complexes, such as $\left[\mathrm{Ni}\left(\mathrm{PPh}_{3}\right)_{3}\right][\mathrm{BF} 4],\left[\mathrm{Ni}\left(\mathrm{PPh}_{3}\right)_{2} \mathrm{X}\right](\mathrm{X}=\mathrm{Cl}, \mathrm{Br})$ and $\left[\mathrm{Ni}-\left(\mathrm{N}^{\wedge} \mathrm{N}\right) \mathrm{R}(\mathrm{L})\right]$ (in which $\left(\mathrm{N}^{\wedge} \mathrm{N}\right) \mathrm{R}=\mathrm{R}$-substituted bulky b-diketiminate and $\mathrm{L}=\mathrm{PCy}_{3}$ or 1,1-bis(diphenylphosphino) (dppm)). This trend was accounted for due to the NHC ligand influence on the $g$ tensor, which must in turn supersede the effects of the vibronic interactions. The spin Hamiltonian parameters of these complexes were all found to be influenced by the changes in NHC ring size, the choice of the substituent (mesityl or tolyl) and the choice of halide. Furthermore, DFT calculations revealed a mixed SOMO of $3 \mathrm{~d}_{z^{2}}$ and $3 \mathrm{~d}_{x^{2}-y^{2}}$ character which is highly dependent on the complex geometry. ${ }^{230}$

In another example, Apfel et al., ${ }^{230,231}$ showed that $\mathrm{Ni}$ and Fe complexes bearing the Triphos(2-((diphenylphosphaneyl)methyl)-2-methylpropane1,3-diyl)bis(diphenylphosphane) and TriphosSi(((methylsilanetriyl)tris(methylene))-tris(diphenylphosphane)) ligands are potential noble metal-free alternatives for the $\mathrm{C}-\mathrm{C}$ cross-coupling of aryl iodides and alkynes. $^{231,232}$ Owing to the high steric hindrance of the Triphos ligand, such Ni complexes did not show any disproportionation of the respective $\mathrm{Ni}^{1+}$ complexes to $\mathrm{Ni}^{0}$ and $\mathrm{Ni}^{2+}$, and also no evidence of any dimerisation to form the di-nickel complex. The Kumada cross-coupling abilities of these complexes were also studied by Apfel et al. ${ }^{223}$ The precatalyst is based on the EPR silent $\mathrm{Ni}^{2+}$ complex, which reverts to $\mathrm{Ni}^{1+}$ following addition of a Grignard reagent to the solution. EPR analysis of the reaction medium revealed small changes to the hyperfine pattern, accompanied with a broadening of the $g$ values after the addition of an aryl-iodides, and also suggested the formation of least one additional $\mathrm{Ni}^{2+}$ species during the catalytic cycle.

In addition to nickel, iron has also attracted considerable attention for its role in cross coupling reactions. Bedford et al., designed and evaluated different iron based catalytic systems, using EPR amongst other techniques, to probe the reaction mechanism. ${ }^{233,234}$ In particular, the efficiency of the iron-phosphine catalyst, based upon the relatively easily accessible bis(diphenylphosphino) ethane (dppe) ligand was investigated. ${ }^{23}$ The dppe-based catalysts demonstrated excellent reactivity in reactions compared to the dpbz-based class of ligands ( $\mathrm{dpbz}=1,2$-bis(diphenylphosphino)benzene). To understand the basis for the similarity in performance, the study focused on the molecular and electronic structures of $\mathrm{Fe}^{1+}$-dppe species. The application of DFT calculations, X-ray crystal structure, and EPR studies confirmed that this low valent iron state adopted a distorted trigonal bipyramidal structure with a low $\operatorname{spin}(S=1 / 2)$ character. In both complexes, the Mulliken spin density was mostly localised on the iron centre, with only a small contribution from the 
ligating $\mathrm{P}$ and halide atoms. The complexes all possessed a rhombic $\boldsymbol{g}$ tensor, consistent with the low spin character of the $\mathrm{Fe}^{1+}$ centre, with spin Hamiltonian parameters of $g_{1}=2.038, g_{2}=2.051$ and $g_{3}=2.132$ for $\mathrm{Fe}^{1+}$-dppe with a Br substituent; and $g_{1}=2.047, g_{2}=2.066$ and $g_{3}=2.167$ for $\mathrm{Fe}^{1+}$-dppe with the $\mathrm{Cl}$ substituent. The EPR spectra also revealed more complicated interactions arising from overlapping super-hyperfine features emanating from ${ }^{31} \mathrm{P}$ and ${ }^{35,37} \mathrm{Cl} /{ }^{79,81} \mathrm{Br}$ nuclei. In addition to these super-hyperfine interactions, underlying quadrupole interactions responsible for the unusual linewidth effects, were also observed.

The progress towards an improved mechanistic understanding of iron and nickel catalysed cross-coupling reactions has dramatically improved over the last decade. EPR has been instrumental in leading this revolution of understanding the role of first-row earth abundant metals in $\mathrm{C}-\mathrm{C}$ cross coupling catalysis. Significant improvements in the use of iron and nickel species that afford greater stability and selectivity, bearing simple salts like ferric salts, ${ }^{235,236}$ or ligands such as bisphosphine, ${ }^{237}$ and $\mathrm{NHC},{ }^{225,238,239}$ is yet to be achieved.

\section{Summary and perspectives}

In the past, certain catalysts dominated the manufacturing industry, from aluminosilicates used for catalytic cracking, to iron and its historical use in the Haber process, to vanadium for sulfuric acid production to platinum and alumina used as versatile bifunctional catalysts to nickel for synthesis gas production. So many of the materials and products we depend upon, such as fuels, fragrances, fertilizers, foodstuffs, pharmaceuticals and fabrics, continue to involve catalysts that were developed over the decades. Just as important, many fundamental molecules and chemicals used for the manufacture of numerous commodity chemicals also rely upon a catalyst, such as benzene, toluene, xylene, terephthalic acid and propylene. Despite this success and dependency, there remains an urgent need to develop new catalysts that can transform or upgrade the readily available raw materials in a sustainable and environmentally friendly manner. This challenge facing the catalysis community is significant and considerable; for example, how can we use cheap abundant elements employing molecular oxygen as an oxidation at ambient conditions in a single pot reaction with no waste. With all these considerations in mind, more and more attention is returning to the role of first row transition metals for catalytic reactions that were previously considered impossible to deliver. And as we explore this potential landscape with the benefit of modern and more powerful analytical techniques, along with improved computational power, we are beginning to see the growing influence and evidence for the involvement of paramagnetic (open shell) centres and free radicals. The dominant and most successful characterisation technique in catalysis over the decades has undoubtedly been NMR, but when paramagnetic systems are in play, these quintessential tools have some limitations. Nevertheless, this is the realm where EPR can contribute and offer it's enormous wealth of information on the paramagnetic states, akin to the diamagnetic states 
comprehensively explored by NMR. The involvement of a paramagnetic state should not therefore hinder nor limit the developments of new catalytic processes, merely because they are hard to study, and instead involve the substantial EPR tool-kit to uncover the nature of the active sites involved in the reaction pathways. In this Chapter, we have therefore tried to exemplify and reveal not only how widespread the paramagnetic state is in very different types of catalytic reactions, but also how much information can be extracted from the EPR data. Regardless of the nature of the catalyst, from heterogeneous to homogeneous to enzymatic, the EPR method can still provide local and longer range information on these open-shell states. If we are to assist the catalysis community in meeting the challenges of developing the next generation of environmentally friendly catalysts, then EPR will be one of the essential characterisation methods required to shed light on the inevitable involvement of the free radical and paramagnetic centres.

\section{Acknowledgements}

The authors gratefully acknowledge funding from the European Union's Horizon 2020 research and innovation programme under the Marie Skłodowska-Curie grant agreement No 813209 entitled PARACAT. The authors would also like to thank the PARACAT academic supervisors, Profs. Mario Chiesa, Andreas Poeppl, Inés García Rubio, and Sabine Van Doorslaer, for constructive discussions and feedback in preparing this Chapter.

\section{References}

1 U. T. Bornscheuer, G. W. Huisman, R. J. Kazlauskas, S. Lutz, J. C. Moore and K. Robins, Nature, 2012, 485, 185.

2 S. Wenda, S. Illner, A. Mell and U. Kragl, Green Chem., 2011, 13, 3007.

3 M. A. Liebert, M. Paoli, J. O. N. Marles-wright and A. Smith, DNA Cell Biol., 2002, 21, 271.

4 A. D. McNaught and A. Wilkinson, Compendium of Chemical Terminology, Wiley, 2nd ed., 1997.

5 R. A. Marcus, J. Chem. Phys., 1956, 24, 966.

6 S. K. Chapman, S. Daff and A. W. Munro, Metal Sites in Proteins and Models, 1997, 39.

7 T. L. Poulos, Chem. Rev., 2014, 114, 3919.

8 P. C. E. Moody and E. L. Raven, Acc. Chem. Res., 2018, 51, 427.

9 P. Atkins, T. Overton, J. Rourke, M. Weller and F. Armstrong, Shriver \& Atkins' Inorganic Chemistry, Oxford University Press, UK, 5th ed., 2009.

10 F. Trandafir, P. Heerdt, M. Fittipaldi, E. Vinck, S. Dewilde, L. Moens and S. Van Doorslaer, Appl. Magn. Reson., 2007, 31, 553.

11 W. R. Hagen, Dalton Trans., 2006, 4415.

12 M. P. Hendrich and P. G. Debrunner, J. Magn. Reson., 1988, 78, 133.

13 M. P. Hendrich and P. G. Debrunner, Biophys. J., 1989, 56, 489.

14 C. P. S. Taylor, Biochim. Biophys. Acta, Protein Struct., 1977, 491, 137.

15 P. J. Alonso, J. I. Martínez and I. García-Rubio, Coord. Chem. Rev., 2007, 251, 12.

16 W. E. Blumberg and J. Peisach, Bioinorganic Chemistry, American Chemical Society, Washington DC, 1971, 271. 
17 C. Aldag, I. A. Gromov, I. García-Rubio, K. Von Koenig, I. Schlichting, B. Jaun and D. Hilvert, Proc. Natl. Acad. Sci. U. S. A., 2009, 106, 5481.

18 G. Zoppellaro, K. L. Bren, A. A. Ensign, E. Harbitz, R. Kaur, H. P. Hersleth, U. Ryde, L. Hederstedt and K. K. Andersson, Biopolym. - Pept. Sci. Sect., 2009, 91, 1064.

19 X. Huang and J. T. Groves, Chem. Rev., 2018, 118, 2491.

20 E. Raven and B. Dunford, Heme Peroxidases, The Royal Society of Chemistry, Cambridge, 2016.

21 P. Nicholls, I. Fita and P. C. Loewen, Adv. Inorg. Chem., 2000, 51, 51.

22 R. Rutter, L. P. Hager, H. Dhonau, M. Hendrich, P. Debrunner and M. Valentine, Biochemistry, 1984, 23, 6809.

23 C. E. Schulz, P. W. Devaney, H. Winkler, P. G. Debrunner, N. Doan, R. Chiang, R. Rutter and L. P. Hager, FEBS Lett., 1979, 103, 102.

24 J. Rittle and M. T. Green, Science, 2010, 330, 933.

25 A. Bencini and D. Gatteschi, Resonance of Exchange Coupled Systems, Springer Berlin Heidelberg, Berlin, Heidelberg, 1990.

26 J. C. Schöneboom, F. Neese and W. Thiel, J. Am. Chem. Soc., 2005, 127, 5840.

27 L. J. Berliner, G. R. Eaton and S. S. Eaton, Distance Measurements in Biological Systems by EPR, Springer US, Boston, MA, vol. 19, 2002.

28 A. L. P. P. Houseman, P. E. Doan, D. B. Goodin and B. M. Hoffman, Biochemistry, 1993, 32, 4430.

29 K. D. Miner, T. D. Pfister, P. Hosseinzadeh, N. Karaduman, L. J. Donald, P. C. Loewen, Y. Lu and A. Ivancich, Biochemistry, 2014, 53, 3781.

30 F. J. Ruiz-Dueñas, R. Pogni, M. Morales, S. Giansanti, M. J. Mate, A. Romero, M. J. Martínez, R. Basosi and A. T. Martínez, J. Biol. Chem., 2009, 284, 7986.

31 D. Dolphin, The Porphyrins, Elsevier, 1st edn, vol. 7, 1978.

32 I. Schaffner, G. Mlynek, N. Flego, D. Pühringer, J. Libiseller-Egger, L. Coates, S. Hofbauer, M. Bellei, P. G. Furtmüller, G. Battistuzzi, G. Smulevich, K. Djinović-Carugo and C. Obinger, ACS Catal., 2017, 7, 7962.

33 M. Alfonso-Prieto, P. Vidossich and C. Rovira, Arch. Biochem. Biophys., 2012, 525, 121.

34 S. H. Kim, R. Perera, L. P. Hager, J. H. Dawson and B. M. Hoffman, J. Am. Chem. Soc., 2006, 128, 5598.

35 R. Davydov, T. M. Makris, V. Kofman, D. E. Werst, S. G. Sligar and B. M. Hoffman, J. Am. Chem. Soc., 2001, 123, 1403.

36 M. J. Benecky, J. E. Frew, N. Scowen, P. Jones and B. M. Hoffman, Biochemistry, 1993, 32, 11929.

37 J. E. Roberts, B. M. Hoffman, R. Rutter and L. P. Hager, J. Biol. Chem., 1981, 256, 2118.

38 J. E. Roberts, B. M. Hoffman, R. Rutter and L. P. Hager, Journal of the American Chemical Society, 1981, 103, 7654.

39 R. Pogni, C. Teutloff, F. Lendzian and R. Basosi, Appl. Magn. Reson., 2007, 31, 509.

40 C. Bernini, R. Pogni, F. J. Ruiz-Dueñas, A. T. Martínez, R. Basosi and A. Sinicropi, Phys. Chem. Chem. Phys., 2011, 13, 5078.

41 T. P. Barrows and T. L. Poulos, Biochemistry, 2005, 44, 14062.

42 V. Guallar and B. Olsen, J. Inorg. Biochem., 2006, 100, 755.

43 I. G. Denisov and S. G. Sligar, Nat. Chem., 2015, 7, 687.

44 H. P. Hersleth, U. Ryde, P. Rydberg, C. H. Görbitz and K. K. Andersson, J. Inorg. Biochem., 2006, 100, 460.

45 H. M. Senn and W. Thiel, Angew. Chem., Int. Ed., 2009, 48, 1198.

46 C. M. Krest, E. L. Onderko, T. H. Yosca, J. C. Calixto, R. F. Karp, J. Livada, J. Rittle and M. T. Green, J. Biol. Chem., 2013, 288, 17074. 
47 M. Zámocký, S. Hofbauer, I. Schaffner, B. Gasselhuber, A. Nicolussi, M. Soudi, K. F. Pirker, P. G. Furtmüller and C. Obinger, Arch. Biochem. Biophys., 2015, 574, 108.

48 C. G. Van Ginkel, G. B. Rikken, A. G. M. Kroon and S. W. M. Kengen, Arch. Microbiol., 1996, 166, 321.

49 S. Hofbauer, I. Schaffner, P. G. Furtmüller and C. Obinger, Biotechnol. J., 2014, 9, 461.

50 I. Schaffner, S. Hofbauer, M. Krutzler, K. F. Pirker, P. G. Furtmüller and C. Obinger, Arch. Biochem. Biophys., 2015, 574, 18.

51 S. Hofbauer, C. Gruber, K. F. Pirker, A. Sündermann, I. Schaffner, C. Jakopitsch, C. Oostenbrink, P. G. Furtmüller and C. Obinger, Biochemistry, 2014, 53, 3145.

52 P. L. Hagedoorn, D. C. De Geus and W. R. Hagen, Eur. J. Biochem., 2002, 269, 4905.

53 K. Stenklo, H. Danielsson Thorell, H. Bergius, R. Aasa and T. Nilsson, J. Biol. Inorg. Chem., 2001, 6, 601.

54 A. Q. Lee, B. R. Streit, M. J. Zdilla, M. M. Abu-Omar and J. L. DuBois, Proc. Natl. Acad. Sci. U. S. A., 2008, 105, 15654.

55 S. Hofbauer and M. Bellei, Biochemistry, 2012, 53, 1689.

56 I. Schaffner, S. Hofbauer, M. Krutzler, K. F. Pirker, M. Bellei, G. Stadlmayr, G. Mlynek, K. Djinovic-Carugo, G. Battistuzzi, P. G. Furtmüller, H. Daims and C. Obinger, Mol. Microbiol., 2015, 96, 1053.

57 A. I. Celis, Z. Geeraerts, D. Ngmenterebo, M. M. Machovina, R. C. Kurker, K. Rajakumar, A. Ivancich, K. R. Rodgers, G. S. Lukat-Rodgers and J. L. Dubois, Biochemistry, 2015, 54, 434.

58 D. C. de Geus, E. A. J. Thomassen, P. L. Hagedoorn, N. S. Pannu, E. van Duijn and J. P. Abrahams, J. Mol. Biol., 2009, 387, 192.

59 A. De Schutter, H. D. Correia, D. M. Freire, M. G. Rivas, A. Rizzi, T. Santos-Silva, P. J. González and S. Van Doorslaer, J. Phys. Chem. B, 2015, 119, 13859.

60 J. M. Keith, M. M. Abu-Omar and M. B. Hall, Inorg. Chem., 2011, 50, 7928.

61 S. Sun, Z. S. Li and S. L. Chen, Dalton Trans., 2014, 43, 973.

62 B. R. Goblirsch, B. R. Streit, J. L. DuBois and C. M. Wilmot, J. Biol. Inorg. Chem., 2010, 15, 879.

63 D. W. Nebert, M. Adesnik, M. J. Coon, R. W. Estabrook, F. J. Gonzalez, F. P. Guengerich, I. C. Gunsalus, E. F. Johnson, B. Kemper and W. Levin, DNA, 1987, 6, 1-11.

64 P. R. Ortiz de Montellano, Cytochrome P450: Structure, Mechanism, and Biochemistry, Springer International Publishing, 4th edn, 2015.

65 T. Omura and R. Sato, J. Biol. Chem., 1964, 239, 2370.

66 P. R. Ortiz de Montellano, Chem. Rev., 2010, 110, 932.

67 E. Sevilla, L. Yuste, R. Moreno and F. Rojo, Environ. Microbiol. Rep., 2017, 9, 797.

68 U. M. Zanger and M. Schwab, Pharmacol. Ther., 2013, 138, 103.

69 S. Jin, T. M. Makris, T. A. Bryson, S. G. Sligar and J. H. Dawson, J. Am. Chem. Soc., 2003, 125, 3406.

70 R. Bernhardt and M. R. Waterman, in The Ubiquitous Roles of Cytochrome P450 Proteins, John Wiley \& Sons, Ltd, 2007, pp. 361-396.

71 H. Thomann, M. Bernardo, D. Goldfarb, P. M. H. Kroneck and V. Ullrich, J. Am. Chem. Soc., 1995, 117, 8243.

72 D. Goldfarb, M. Bernardo, H. Thomann, P. M. H. Kroneck and V. Ullrich, J. Am. Chem. Soc., 1996, 118, 2686. 
73 E. G. Funhoff, U. Bauer, I. Garcia-Rubio, B. Witholt and J. B. Van Beilen, J. Bacteriol., 2006, 188, 5220.

74 S. Stoll, Y. T. Lee, M. Zhang, R. F. Wilson, R. D. Britt and D. B. Goodin, Proc. Natl. Acad. Sci. U. S. A., 2012, 109, 12888.

75 M. J. Hintz, D. M. Mock, L. L. Peterson, K. Tuttle and J. A. Peterson, J. Biol. Chem., 1982, 257, 14324.

76 I. Schlichting, J. Berendzen, K. Chu, A. M. Stock, S. A. Maves, D. E. Benson, R. M. Sweet, D. Ringe, G. A. Petsko and S. G. Sligar, Science, 2000, 287, 1615.

77 I. G. Denisov, Phys. Inorg. Chem.: Princ., Methods, Models, 2010, 109.

78 J. Rittle, M. T. Green and C. Bond, Science, 2014, 933, 933.

79 X. He and P. R. Ortiz De Montellano, J. Biol. Chem., 2004, 279, 39479.

80 A. W. Munro, K. J. McLean, J. L. Grant and T. M. Makris, Biochem. Soc. Trans., 2018, 46, 183.

81 A. Ciaramella, G. Catucci, G. Gilardi and G. Di, Int. J. Biol. Macromol., 2019, 140, 577.

82 A. W. Munro, D. G. Leys, K. J. Mclean, K. R. Marshall, T. W. B. Ost, S. Daff, C. S. Miles, S. K. Chapman, D. A. Lysek, C. C. Moser, C. C. Page, L. Dutton, D. G. Leys, K. R. Marshall, C. S. Miles, S. K. Chapman, C. C. Page and L. Dutton, 2002, 27, 250.

83 A. Ciaramella, G. Catucci, G. Di Nardo, S. J. Sadeghi and G. Gilardi, Nat. Biotechnol., 2020, 54, 71.

84 A. Shamiri, M. H. Chakrabarti, S. Jahan, M. A. Hussain, W. Kaminsky, P. V. Aravind and W. A. Yehye, Materials, 2014, 7, 5069-5108.

85 J. Boor, Ziegler - Natta Catalysts and Polymerizations, 1979.

86 R. P. Chaplin, R. P. Burford, G. J. Tory and S. Kirby, Polymer, 1987, 28, 1418.

87 O. P. Tkachenko, A. V. Kucherov, L. M. Kustov, V. Virkkunen, T. Leinonen and P. Denifl, Materials, 2017, 10, 1.

88 R. Credendino, Y. Minenkov, D. Liguori, F. Piemontesi, A. Melchior, G. Morini, M. Tolazzi and L. Cavallo, Phys. Chem. Chem. Phys., 2017, 19, 26996.

89 L. Cavallo, S. Del Piero, J. M. Ducéré, R. Fedele, A. Melchior, G. Morini, F. Piemontesi and M. Tolazzi, J. Phys. Chem. C, 2007, 111, 4412.

90 E. Morra, E. Giamello and M. Chiesa, J. Magn. Reson., 2017, 280, 89.

91 E. Morra, E. Giamello and M. Chiesa, Chem. - Eur. J., 2014, 20, 7381.

92 M. Morra, E. Giamello, E. Van Doorslaer, S. Antinucci, G. D’Amore, A. Busico and V. Chiesa, Angew. Chem., 2015, 54, 1.

93 F. Allouche, D. Klose, C. P. Gordon, A. Ashuiev, M. Wörle, V. Kalendra, V. Mougel, C. Copéret and G. Jeschke, Angew. Chem., Int. Ed., 2018, 57, 14533.

94 E. Morra, A. Cuko, S. Maurelli, G. Berlier, P. Ugliengo and M. Chiesa, J. Phys. Chem. C, 2015, 119, 26046.

95 P. Brant and A. N. Speca, Macromolecules, 1987, 20, 2740.

96 D. R. Wilson and W. E. Smith, Inorg. Chim. Acta, 1985, 102, 151.

97 J. C. W. Chien, J. C. Wu and C. I. Kuo, Am. Chem. Soc. Polym. Prepr. Div. Polym. Chem, 1983, 24, 109.

98 E. I. Koshevoy, T. B. Mikenas, V. A. Zakharov, A. M. Volodin and R. M. Kenzhin, Catal. Commun., 2014, 48, 38.

99 T. B. Mikenas, E. I. Koshevoy, V. A. Zakharov and M. I. Nikolaeva, Macromol. Chem. Phys., 2014, 215, 1707.

100 E. I. Koshevoy, T. B. Mikenas, V. A. Zakharov, A. A. Shubin and A. A. Barabanov, J. Phys. Chem. C, 2016, 120, 1121.

101 J. Schmidt, T. Risse, H. Hamann and H. J. Freund, J. Chem. Phys., 2002, 116, 10861.

102 J. P. Hogan and R. L. Banks, U.S. Pat., US2825721, 1954. 
103 B. M. Weckhuysen and R. A. Schoonheydt, Catal. Today, 1999, 51, 215.

104 M. P. McDaniel, in Advances in Catalysis, vol. 53, 2010, pp. 123-606.

105 E. Groppo, G. A. Martino, A. Piovano and C. Barzan, ACS Catal., 2018, 8, 10846.

106 B. M. Weckhuysen, L. M. De Ridder and R. A. Schoonheydt, J. Phys. Chem., 1993, 97, 4756.

107 B. M. Weckhuysen, R. A. Schoonheydt, F. E. Mabbs and D. Collison, J. Chem. Soc., Faraday Trans., 1996, 92, 2431.

108 E. Morra, G. A. Martino, A. Piovano, C. Barzan, E. Groppo and M. Chiesa, J. Phys. Chem. C, 2018, 122, 21531.

109 C. Brown, J. Krzystek, R. Achey, A. Lita, R. Fu, R. W. Meulenberg, M. Polinski, N. Peek, Y. Wang, L. J. van de Burgt, S. Profeta, A. E. Stiegman and S. L. Scott, ACS Catal., 2015, 5, 5574.

110 C. Brown, A. Lita, Y. Tao, N. Peek, M. Crosswhite, M. Mileham, J. Krzystek, R. Achey, R. Fu, J. K. Bindra, M. Polinski, Y. Wang, L. J. van de Burgt, D. Jeffcoat, S. Profeta, A. E. Stiegman and S. L. Scott, ACS Catal., 2017, 7,7442 .

111 C. Copéret, F. Allouche, K. W. Chan, M. P. Conley, M. F. Delley, A. Fedorov, I. B. Moroz, V. Mougel, M. Pucino, K. Searles, K. Yamamoto and P. A. Zhizhko, Angew. Chem., Int. Ed., 2018, 57, 6398.

112 M. F. Delley, F. Núñez-Zarur, M. P. Conley, A. Comas-Vives, G. Siddiqi, S. Norsic, V. Monteil, O. V. Safonova and C. Copéret, Proc. Natl. Acad. Sci. U. S. A., 2015, 112, E4505.

113 M. F. Delley, G. Lapadula, F. Núñez-Zarur, A. Comas-Vives, V. Kalendra, G. Jeschke, D. Baabe, M. D. Walter, A. J. Rossini, A. Lesage, L. Emsley, O. Maury and C. Copéret, J. Am. Chem. Soc., 2017, 139, 8855.

114 D. S. McGuinness, Chem. Rev., 2011, 111, 2321.

115 D. S. McGuinness, P. Wasserscheid, W. Keim, C. Hu, U. Englert, J. T. Dixon and C. Grove, Chem. Commun., 2003, 3, 334.

116 A. Brückner, J. K. Jabor, A. E. C. McConnell and P. B. Webb, Organometallics, 2008, 27, 3849.

117 R. Grauke, R. Schepper, J. Rabeah, R. Schoch, U. Bentrup, M. Bauer and A. Brückner, ChemCatChem, 2019, 1.

118 L. McDyre, E. Carter, K. J. Cavell, D. M. Murphy, J. A. Platts, K. Sampford, B. D. Ward, W. F. Gabrielli, M. J. Hanton and D. M. Smith, Organometallics, 2011, 30, 4505.

119 E. Carter, K. J. Cavell, W. F. Gabrielli, M. J. Hanton, A. J. Hallett, L. McDyre, J. A. Platts, D. M. Smith and D. M. Murphy, Organometallics, 2013, 32, 1924.

120 S. L. J. Luckham, A. Folli, J. A. Platts, E. Richards and D. M. Murphy, Organometallics, 2019, DOI: 10.1021/acs.organomet.9b00226.

121 G. Leofanti, G. Tozzola, M. Padovan, G. Petrini, S. Bordiga and A. Zecchina, Catal. Today, 1997, 34, 307.

122 B. Smit and T. L. M. Maesen, Nature, 2008, 451, 671-678.

123 X. F. Yang, A. Wang, B. Qiao, J. Li, J. Liu and T. Zhang, Acc. Chem. Res., 2013, 46, 1740.

124 D. Goldfarb, Phys. Chem. Chem. Phys., 2006, 8, 2325.

125 A. Brückner, Chem. Soc. Rev., 2010, 39, 4673-4684.

126 G. Martini, M. F. Ottaviani and M. Romanelli, J. Colloid Interface Sci., 1987, 115, 87.

127 M. Mendt, F. Gutt, N. Kavoosi, V. Bon, I. Senkovska, S. Kaskel and A. Pöppl, J. Phys. Chem. C, 2016, 120, 14246.

128 A. Poeppl, T. Rudolf, P. Manikandan and D. Goldfarb, J. Am. Chem. Soc., 2000, 122, 10194. 
129 M. K. Wang and J. H. Lunsford, Notes Electron Paramagnetic Resonance Evidence for the Presence of Aluminum at Adsorption Sites on Decationated Zeolites, Elsevier Publishing Co, vol. 72, 1968.

130 D. Chen, H. Xing, C. Wang and Z. Su, J. Mater. Chem. A, 2016, 4, 2657.

131 M. A. Nasalevich, C. H. Hendon, J. G. Santaclara, K. Svane, B. Van Der Linden, S. L. Veber, M. V. Fedin, A. J. Houtepen, M. A. Van Der Veen, F. Kapteijn, A. Walsh and J. Gascon, Sci. Rep., 2016, 6, 1.

132 J. Y. Ying, C. P. Mehnert and M. S. Wong, Angew. Chem. Int. Ed., 1999, 38, 56.

133 Y. J. Kim, D. Y. Jung, K. P. Hong and G. Demazeau, Solid State Sci., 2001, 3, 837.

134 C. S. Cundy, Clay Miner., 1990, 25, 244.

135 A. Primo and H. Garcia, Chem. Soc. Rev., 2014, 43, 7548.

136 A. Corma, J. Catal., 2003, 216, 298.

137 L. Kevan, Acc. Chem. Res., 1987, 20, 1.

138 B. M. Weckhuysen, R. Heidler and R. A. Schoonheydt, in Characterization I. Molecular Sieves - Science and Technology, ed. H. G. Karge, J. Weitkamp, Springer Berlin Heidelberg, Berlin, 2004, 295.

139 M. H. Groothaert, K. Pierloot, A. Delabie and R. A. Schoonheydt, Phys. Chem. Chem. Phys., 2003, 5, 2135.

140 D. Goldfarb and K. Zukerman, Chem. Phys. Lett., 1990, 171, 167.

141 A. Godiksen, F. N. Stappen, P. N. R. Vennestrøm, F. Giordanino, S. B. Rasmussen, L. F. Lundegaard and S. Mossin, J. Phys. Chem. C, 2014, 118, 23126.

142 J. Dědeček, Z. Sobalík and B. Wichterlová, Catal. Rev.: Sci. Eng., 2012, 54, 135-223.

143 U. Sakaguchi and A. W. Addison, J. Chem. Soc., Dalton Trans., 1979, 600.

144 A. Godiksen, P. N. R. Vennestrøm, S. B. Rasmussen and S. Mossin, Top. Catal., 2017, 60, 13.

145 J. Peisach and W. E. Blumberg, Arch. Biochem. Biophys., 1974, 165, 691.

146 P. J. Carl and S. C. Larsen, J. Phys. Chem. B, 2000, 104, 6568.

147 M. Moreno-González, T. Blasco, K. Góra-Marek, A. E. Palomares and A. Corma, Catal. Today, 2014, 227, 123.

148 H. G. Karge, J. P. Lange, A. Gutsze and M. Łaniecki, J. Catal., 1988, 114, 144.

149 E. V. Kondratenko and A. Brückner, J. Catal., 2010, 274, 111.

150 E. Berrier, O. Ovsitser, E. V. Kondratenko, M. Schwidder, W. Grünert and A. Brückner, J. Catal., 2007, 249, 67.

151 G. I. Panov, G. A. Sheveleva, A. S. Kharitonov, V. N. Romannikov and L. A. Vostrikova, Appl. Catal., A, 1992, 82, 31.

152 A. Huang, Y. He, Y. Zhou, Y. Zhou, Y. Yang, J. Zhang, L. Luo, Q. Mao, D. Hou and J. Yang, J. Mater. Sci., 2019, 54, 949.

153 C. J. Doonan and C. J. Sumby, CrystEngComm, 2017, 19, 4045.

154 H. Furukawa, K. E. Cordova, M. O'Keeffe and O. M. Yaghi, Science, 2013, DOI: $10.1126 /$ science.1230444.

155 F. Jeremias, V. Lozan, S. K. Henninger and C. Janiak, Dalton Trans., 2013, 42, 15967.

156 Y. Zhao, Z. Song, X. Li, Q. Sun, N. Cheng, S. Lawes and X. Sun, Energy Storage Mater., 2016, 2, 35.

157 C. Serre, F. Millange, C. Thouvenot, M. Noguès, G. Marsolier, D. Louër and G. Férey, J. Am. Chem. Soc., 2002, 124, 13519.

158 C. Xu, R. Fang, R. Luque, L. Chen and Y. Li, Coord. Chem. Rev., 2019, 388, 268.

159 J. Long, S. Wang, Z. Ding, S. Wang, Y. Zhou, L. Huang and X. Wanga, Chem. Commun., 2012, 48, 11656. 
160 V. R. Remya and M. Kurian, Int. Nano Lett., 2019, 9, 17.

161 H. Li, M. Eddaoudi, M. O’Keeffe and O. M. Yaghi, Nature, 1999, 402, 276.

162 S. Yuan, J. S. Qin, J. Li, L. Huang, L. Feng, Y. Fang, C. Lollar, J. Pang, L. Zhang, D. Sun, A. Alsalme, T. Cagin and H. C. Zhou, Nat. Commun., 2018, DOI: 10.1038/s41467-018-03102-5.

163 A. Kultaeva, T. Biktagirov, P. Neugebauer, H. Bamberger, J. Bergmann, J. Van Slageren, H. Krautscheid and A. Pöppl, J. Phys. Chem. C, 2018, 122, 26642.

164 J. Bitzer, S. Otterbach, K. Thangavel, A. Kultaeva, R. Schmid, A. Pöppl and W. Kleist, Chem. - Eur. J., 2019, DOI: 10.1002/chem.201905596.

165 M. Mendt, B. Jee, N. Stock, T. Ahnfeldt, M. Hartmann, D. Himsl and A. Pöppl, J. Phys. Chem. C, 2010, 114, 19443.

166 M. Mendt, B. Jee, D. Himsl, L. Moschkowitz, T. Ahnfeldt, N. Stock, M. Hartmann and A. PÖppl, Appl. Magn. Reson., 2014, 45, 269.

167 M. Mendt, B. Barth, M. Hartmann and A. Pöppl, J. Chem. Phys., 2017, DOI: $10.1063 / 1.4995551$.

168 M. N. Timofeeva, V. N. Panchenko, N. A. Khan, Z. Hasan, I. P. Prosvirin, S. V. Tsybulya and S. H. Jhung, Appl. Catal., A, 2017, 529, 167.

169 L. Mitchell, P. Williamson, B. Ehrlichov, A. E. Anderson, V. R. Seymour, S. E. Ashbrook, N. Acerbi, L. M. Daniels, R. I. Walton, M. L. Clarke and P. A. Wright, Chem. - Eur. J., 2014, 20, 17185.

170 J. Spencer, A. Folli, E. Richards and D. M. Murphy, in Electron Paramagnetic Resonance: Volume 26, The Royal Society of Chemistry, vol. 26, 2019, pp. 130-170.

171 Y. Horiuchi, T. Toyao, M. Saito, K. Mochizuki, M. Iwata, H. Higashimura, M. Anpo and M. Matsuoka, J. Phys. Chem. C, 2012, 116, 20848.

172 X. Zhao, B. Pattengale, D. Fan, Z. Zou, Y. Zhao, J. Du, J. Huang and C. Xu, ACS Energy Lett., 2018, 3, 2520.

173 P. Ji, X. Feng, P. Oliveres, Z. Li, A. Murakami, C. Wang and W. Lin, J. Am. Chem. Soc., 2019, 141, 14878.

174 H. Hennig, Coord. Chem. Rev., 1999, 182, 101.

175 C. K. Prier, D. A. Rankic and D. W. C. MacMillan, Chem. Rev., 2013, 113, 5322.

176 M. Goswami, A. Chirila, C. Rebreyend and B. de Bruin, EPR Spectroscopy as a Tool in Homogeneous Catalysis Research, Springer US, vol. 58, 2015.

177 S. D. McCann and S. S. Stahl, Acc. Chem. Res., 2015, 48, 1756.

178 C. E. Elwell, N. L. Gagnon, B. D. Neisen, D. Dhar, A. D. Spaeth, G. M. Yee and W. B. Tolman, Chem. Rev., 2017, 117, 2059.

179 A. E. Wendlandt, A. M. Suess and S. S. Stahl, Angew. Chem. Int. Ed., 2011, 50, 11062.

180 Z. Shi, C. Zhang, C. Tang and N. Jiao, Chem. Soc. Rev., 2012, 41, 3381.

181 S. E. Allen, R. R. Walvoord, R. Padilla-Salinas and M. C. Kozlowski, Chem. Rev., 2013, 113, 6234.

182 B. Su, Z. Cao and Z. Shi, Acc. Chem. Res., 2015, 48, 886.

183 E. Carter and D. M. Murphy, Top. Catal., 2015, 58, 759.

184 E. Richards, D. M. Murphy and M. Che, Res. Chem. Intermed., 2019, 45, 5763.

185 A. Cybula, J. B. Priebe, M. M. Pohl, J. W. Sobczak, M. Schneider, A. Zielińska-Jurek, A. Brückner and A. Zaleska, Appl. Catal., B, 2014, 152-153, 202.

186 J. B. Priebe, M. Karnahl, H. Junge, M. Beller, D. Hollmann and A. Brückner, Angew. Chem., Int. Ed., 2013, 52, 11420.

187 K. Kalyanasundaram, Coord. Chem. Rev., 1982, 46, 159. 
188 H. Y. Wang, E. Mijangos, S. Ott and A. Thapper, Angew. Chem. Int. Ed., 2014, 53, 14499.

189 M. L. Rigsby, S. Mandal, W. Nam, L. C. Spencer, A. Llobet and S. S. Stahl, Chem. Sci., 2012, 3, 3058.

190 Y. I. Cho, D. M. Joseph and M. J. Rose, Inorg. Chem., 2013, 52, 13298.

191 J. G. Mcalpin, Y. Surendranath, M. Dinca, T. A. Stich, S. A. Stoian, W. H. Casey, D. G. Nocera and R. D. Britt, J. Am. Chem. Soc., 2010, 132, 6882 .

192 D. Hollmann, F. Gärtner, R. Ludwig, E. Barsch, H. Junge, M. Blug, S. Hoch, M. Beller and A. Brückner, Angew. Chem. Int. Ed., 2011, 50, 10246.

193 L. L. Tinker and S. Bernhard, Inorg. Chem., 2009, 48, 10507.

194 F. Gärtner, A. Boddien, E. Barsch, K. Fumino, S. Losse, H. Junge, D. Hollmann, A. Brückner, R. Ludwig and M. Beller, Chem. - Eur. J., 2011, 17, 6425.

195 N. A. Romero and D. A. Nicewicz, Chem. Rev., 2016, 116, 10075.

196 H. Junge, N. Rockstroh, S. Fischer, A. Brückner, R. Ludwig, S. Lochbrunner, O. Kühn and M. Beller, Inorganics, 2017, 5, 14.

197 X. Li, M. Wang, S. Zhang, J. Pan, Y. Na, J. Liu, B. Åkermark and L. Sun, J. Phys. Chem. B, 2008, 112, 8198.

198 C. Orain, F. Quentel and F. Gloaguen, ChemSusChem, 2014, 7, 638.

199 D. Rehorek and H. Hennig, Can. J. Chem., 1982, 60, 1565.

200 A. Hossain, A. Bhattacharyya and O. Reiser, Science, 2019, 364, eaav9713.

201 O. Reiser, Acc. Chem. Res., 2016, 49, 1990.

202 O. S. Wenger, J. Am. Chem. Soc., 2018, 140, 13522.

203 J. Sauvageb, J. Chem. Soc., Chem. Commun., 1987, 546.

204 C. D. Matier, J. Schwaben, J. C. Peters and G. C. Fu, J. Am. Chem. Soc., 2017, 139, 17707.

205 A. Hossain, S. Engl, E. Lutsker and O. Reiser, ACS Catal., 2019, 9, 1103.

206 M. Bourrez, M. Orio, F. Molton, H. Vezin, C. Duboc, A. Deronzier and S. Chardon-Noblat, Angew. Chem., Int. Ed., 2014, 53, 240.

207 N. A. Stamos, E. Ferentinos, M. Chrysina, C. P. Raptopoulou, V. Psycharis, Y. Sanakis, D. A. Pantazis, P. Kyritsis and G. Mitrikas, Inorg. Chem., 2020, 59, 3666.

208 B. L. Ryland, S. D. McCann, T. C. Brunold and S. S. Stahl, J. Am. Chem. Soc., 2014, 136, 12166.

209 S. D. McCann and S. S. Stahl, J. Am. Chem. Soc., 2016, 138, 199.

210 J. M. Hoover, B. L. Ryland and S. S. Stahl, J. Am. Chem. Soc., 2013, 135, 2357.

211 M. C. Ryan, L. D. Whitmire, S. D. McCann and S. S. Stahl, Inorg. Chem., 2019, 58, 10194.

212 S. D. McCann, J. P. Lumb, B. A. Arndtsen and S. S. Stahl, ACS Cent. Sci., 2017, 3, 314.

213 Y. Sasano, S. Nagasawa, M. Yamazaki, M. Shibuya, J. Park and Y. Iwabuchi, The Journal of Organic Chemistry, 2014, 79, 3236.

214 J. E. Steves and S. S. Stahl, J. Am. Chem. Soc., 2013, 135, 15742.

215 E. C. Hayes, T. R. Porter, C. J. Barrows, W. Kaminsky, J. M. Mayer and S. Stoll, J. Am. Chem. Soc., 2016, 138, 4132.

216 T. R. Porter, D. Capitao, W. Kaminsky, Z. Qian and J. M. Mayer, Inorg. Chem., 2016, 55, 5467.

217 F. E. Mabbs and D. Collison, Electron Paramagnetic Resonance of d Transition Metal Compounds, Elsevier, 1992.

218 K. Rajabimoghadam, Y. Darwish, U. Bashir, D. Pitman, S. Eichelberger, M. A. Siegler, M. Swart and I. Garcia-Bosch, J. Am. Chem. Soc., 2018, 140, 16625.

219 J. W. Whittaker, Chem. Rev., 2003, 103, 2347. 
220 A. Jehdaramarn, S. Pornsuwan, P. Chumsaeng, K. Phomphrai and P. Sangtrirutnugul, New J. Chem., 2018, 42, 654.

221 I. Gamba, I. Mutikainen, E. Bouwman, J. Reedijk and S. Bonnet, Eur. J. Inorg. Chem., 2013, 115.

222 A. Soroceanu, M. Cazacu, S. Shova, C. Turta, J. Kožíšek, M. Gall, M. Breza, P. Rapta, T. C. O. Mac Leod, A. J. L. Pombeiro, J. Telser, A. A. Dobrov and V. B. Arion, Eur. J. Inorg. Chem., 2013, 1458.

223 L. Iffland, A. Petuker, M. van Gastel and U. P. Apfel, Inorganics, 2017, 5, 78.

224 M. L. Neidig, S. H. Carpenter, D. J. Curran, J. C. Demuth, V. E. Fleischauer, T. E. Iannuzzi, P. G. N. Neate, J. D. Sears and N. J. Wolford, Acc. Chem. Res., 2019, 52, 140.

225 W. J. M. Blackaby, S. Sabater, R. C. Poulten, M. J. Page, A. Folli, V. Krewald, M. F. Mahon, D. M. Murphy, E. Richards and M. K. Whittlesey, Dalton Trans., 2018, 47, 769.

226 S. Si, B. Mallick, M. Van Gastel and U. Apfel, Dalton Trans., 2017, 46, 907.

227 R. B. Bedford, Acc. Chem. Res., 2015, 48, 1485.

228 S. B. Tailor, M. Manzotti, S. Asghar, B. J. S. Rowsell, S. L. J. Luckham, H. A. Sparkes and R. B. Bedford, Organometallics, 2019, 38, 1770.

229 S. Pelties, E. Carter, A. Folli, M. F. Mahon, D. M. Murphy, M. K. Whittlesey and R. Wolf, Inorg. Chem., 2016, 55, 11006.

230 M. J. Page, W. Y. Lu, R. C. Poulten, E. Carter, A. G. Algarra, B. M. Kariuki, S. A. MacGregor, M. F. Mahon, K. J. Cavell, D. M. Murphy and M. K. Whittlesey, Chem. - Eur. J., 2013, 19, 2158.

231 A. Petuker, M. El-Tokhey, M. L. Reback, B. Mallick and U. P. Apfel, ChemistrySelect, 2016, 1, 2717.

232 A. Petuker, C. Merten and U. P. Apfel, Eur. J. Inorg. Chem., 2015, 2015, 2139.

233 R. B. Bedford, E. Carter, P. M. Cogswell, N. J. Gower, M. F. Haddow, J. N. Harvey, D. M. Murphy, E. C. Neeve and J. Nunn, Angew. Chem. Int. Ed., 2013, 52, 1285.

234 R. B. Bedford, P. B. Brenner, E. Carter, P. M. Cogswell, M. F. Haddow, J. N. Harvey, D. M. Murphy, J. Nunn and C. H. Woodall, Angew. Chem., Int. Ed., 2014, 53, 1804.

235 S. B. Muñoz, S. L. Daifuku, J. D. Sears, T. M. Baker, S. H. Carpenter, W. W. Brennessel and M. L. Neidig, Angew. Chem., Int. Ed., 2018, 57, 6496.

236 S. B. Muñoz, S. L. Daifuku, W. W. Brennessel and M. L. Neidig, J. Am. Chem. Soc., 2016, 138, 7492.

237 H. Takaya, S. Nakajima, N. Nakagawa, K. Isozaki, T. Iwamoto, R. Imayoshi, N. J. Gower, L. Adak, T. Hatakeyama, T. Honma, M. Takagaki, Y. Sunada, H. Nagashima, D. Hashizume, O. Takahashi and M. Nakamura, Bull. Chem. Soc. Jpn., 2015, 88, 410.

238 M. Guisán-Ceinos, F. Tato, E. Buñel, P. Calle and D. J. Cárdenas, Chem. Sci., 2013, 4, 1098.

239 Q. Liang and D. Song, Chem. Soc. Rev., 2020, 49, 1209. 